\title{
Influence of a closed-loop controlled laser metal wire deposition process of S Al 5356 on the quality of manufactured parts before and after subsequent machining
}

\author{
Dina Becker ${ }^{1}$. Steffen Boley ${ }^{2} \cdot$ Rocco Eisseler $^{1} \cdot$ Thomas Stehle $^{1} \cdot$ Hans-Christian Möhring ${ }^{1} \cdot$ Volkher Onuseit $^{2}$. \\ Max Hoßfeld ${ }^{2}$. Thomas Graf ${ }^{2}$
}

Received: 26 August 2020 / Accepted: 5 February 2021

(C) The Author(s) 2021, corrected publication 2021

\begin{abstract}
This paper describes the interdependence of additive and subtractive manufacturing processes using the production of test components made from S Al 5356. To achieve the best possible part accuracy and a preferably small wall thickness already within the additive process, a closed loop process control was developed and applied. Subsequent machining processes were nonetheless required to give the components their final shape, but the amount of material in need of removal was minimised. The effort of minimising material removal strongly depended on the initial state of the component (wall thickness, wall thickness constancy, microstructure of the material and others) which was determined by the additive process. For this reason, knowledge of the correlations between generative parameters and component properties, as well as of the interdependency between the additive process and the subsequent machining process to tune the former to the latter was essential. To ascertain this behaviour, a suitable test part was designed to perform both additive processes using laser metal wire deposition with a closed loop control of the track height and subtractive processes using external and internal longitudinal turning with varied parameters. The so manufactured test parts were then used to qualify the material deposition and turning process by criteria like shape accuracy and surface quality.
\end{abstract}

Keywords Additive-subtractive manufacturing $\cdot$ Laser metal deposition $\cdot$ Closed-loop control $\cdot$ AM post-processing · Machining $\cdot$ Machining quality

\section{Introduction}

Additive manufacturing processes offer the possibility of near-net-shape production of components with locally adapted mechanical properties, which can be optimized in accordance with the load by downstream process steps, as shown by [1]. This leads to a double conservation of resources, by minimising the materials used for component manufacturing, and by ensuring that the component functions in a load-compatible manner. In addition, additive processes allow the production of parts that cannot

Dina Becker

dina.becker@ifw.uni-stuttgart.de

1 Institute for Machine Tools (IfW), University of Stuttgart, Holzgartenstraße 17, 70174 Stuttgart, Germany

2 Institut für Strahlwerkzeuge (IFSW), University of Stuttgart, Pfaffenwaldring 43, 70569 Stuttgart, Germany be manufactured using conventional production methods or require joining from several components. Furthermore, additive manufacturing offers a wide range of possibilities for lightweight construction, the integration of mechanical or electronic functions and the individualization of automotive engineering components. However, it was mentioned that additively manufactured components generally do not have the required surface quality and shape accuracy for functional surfaces such as flanges, guides, bearing seats or similar and are therefore in most cases reworked by machining [2]. Research in the area of hybrid processes noted an interaction between the generation parameters of the additive process and the metal-cutting finishing process, which made a combined consideration of both processes indispensable [3]. By means of laser-based additive manufacturing processes, such as laser cladding or selective laser melting (Laser Powder Bed Fusion-LPBF), metals are processed in the form of powder or wire, whereby strengths can be achieved that are comparable to those of conventionally 
manufactured components. The available methods have process-specific advantages and disadvantages. For example, higher deposition rates are achieved in deposition welding through a significantly higher laser power of several $\mathrm{kW}$ in comparison to only some hundred watts in powder bedbased processes. The use of wire opens the possibility of producing closed, empty cavities, which is not possible with any other powder based additive manufacturing process for metals, because the excessive powder gets stuck in the cavities. On the other hand, the surface qualities are significantly better with the powder-bed-based processes and, by means of adapted process strategies, graded component states can be created, and the porosity can be varied.

Although quality is an important factor, to make AM-processes competitive in contrast to conventional manufacturing processes, the deposition rate must be increased vastly to reduce production time. As already mentioned in the case of deposition welding, this can be achieved using filler metals such as wire. An AM-process who also uses this filler metal is the laser metal wire deposition process (LMWD). LMWD has been improved over the last years to produce simple low accuracy 3D printed parts. Different strategies in 3D printing with wire have been evaluated [4]. Also aluminium as filler metal has been used by some sources to produce simple cylindrical parts [5].

The quality of the components produced with the LMWD process can be improved by using a so-called height control. The height control regulates the material feed in the process to compensate for irregularities in the substrate or previous tracks. A successful control of the track heights by distance measurement with a triangulation sensor and adjustment of the wire speed has already been realised [6]. The track height deviation was compensated for by means of preceding measurement. The difference between controlled and uncontrolled produced cylinders was shown. An intra-layer toolpath generation control procedure to increase the quality of the deposition process was also implemented, where an static camera system was used to observe the process [7]. For the LMWD process in specific, some sources demonstrated a track height control for laser metal deposition with powder [8].

In this study the influence of a closed-loop controlled LMWD process on the part accuracy as well as for the necessary subsequent machining process was investigated. In the generative LMWD process, the laser beam melts the wire and the base material. The molten material bonds firmly with the base material or the previous layer and solidifies again until a small elevation remains. When the individual weld paths overlap precisely, the desired shape is progressively applied. The high temperature gradients which occur in the LMWD-process create stresses which can lead to dimensional deviations because of the subsequent relaxation. Due to the component requirements regarding e.g. dimensional accuracy, mechanical properties, and surface quality, the generative LMWD process thus represents a part of an overall process chain with pre- and post-processes. The time required for component production in the LMWD process can be in the range of several hours and depends primarily on the number of layers (slices) to be fabricated and the combination of process parameters. The economic efficiency along the process chain can thus be increased by reducing the number of machine hours in the LMWD process and the subsequent machining by reducing component scrap.

The resulting surface quality and shape deviations of the additive production process are analysed and the required oversize from the surface and shape to obtain a defined dimension through the process chain with subsequent machining is derived by producing single line build ups with a minimal wall thickness using a cylinder geometry for a continuous process and easy processing afterwards. The investigation is done with fixed process parameters for a stable production process with $1 \mathrm{~mm}$ wire to produce cylinders with the same height and to test a developed closedloop track height control for better accuracy and smaller wall thicknesses. In the first part, this study presents the investigations on the wall thickness of the samples, which were generated under varied process conditions and parameters by LMWD, using aluminium wire as filler metal. In the second part the accuracy of the test components is examined and discussed. In the third part the results of the machining post-process for the quality improvement of the test components are presented.

\section{Test sample geometry}

The test sample should be an illustration of the most important and most frequently occurring design elements in real components. It should have characteristics for the analysis of the influence of the applied process technologies and the machine kinematics. It should allow robust applicability of common measuring methods for the evaluation of form accuracy and testing of mechanical properties and give the possibility of estimating the expenditure of time, energy, and costs for economic feasibility studies on real components.

In contrast to conventional machining processes such as milling and drilling with machining centres (VDI 2851), there are no standardized sample geometries for the evaluation of additive manufacturing processes. For FLM ("Fused Layer Modelling") as well as in laser-based LBM ("laser beam melting") and EBM ("electron beam melting") processes, samples with different geometries are used in product/process development. The use of a rectangular parallelepiped [9], a tensile test geometry [10, 11], a solid cylindrical rod [12], and the combined use of a cube and a 
parallelepiped [13] are known for the evaluation of AMprocesses. In the following, requirements and criteria are described which are placed on a sample for the assessment of the additive-subtractive process chain using the example of the laser metal wire deposition (LMWD) process. The corresponding properties and characteristics are then derived from this.

To carry out initial basic investigations on the LMWD process, the basic geometric shape "cylinder", as shown in Fig. 1, was selected and used in the investigations described here. It was considered that all occurring process technologies (additive manufacturing, a possible thermal treatment as well as the subtractive post-processing) can be robustly tested and evaluated by using this sample geometry.
The design elements of the developed sample geometries result in the following objects of investigation, which can be viewed during the overall manufacturing process (Table 1).

The selected test part geometry is sufficient to investigate the effects of the machine kinematics on the production process since a round form can only be printed with all three available axes of the tool head or one axis of the tool head and one of the machine table. Furthermore, it represents basic features that can be found on almost all industrially relevant parts. In addition, the cylindrical shape is easy to machine in post-processing, and evaluation methods of this shape are also well established to assess the stability of the LMWD process.

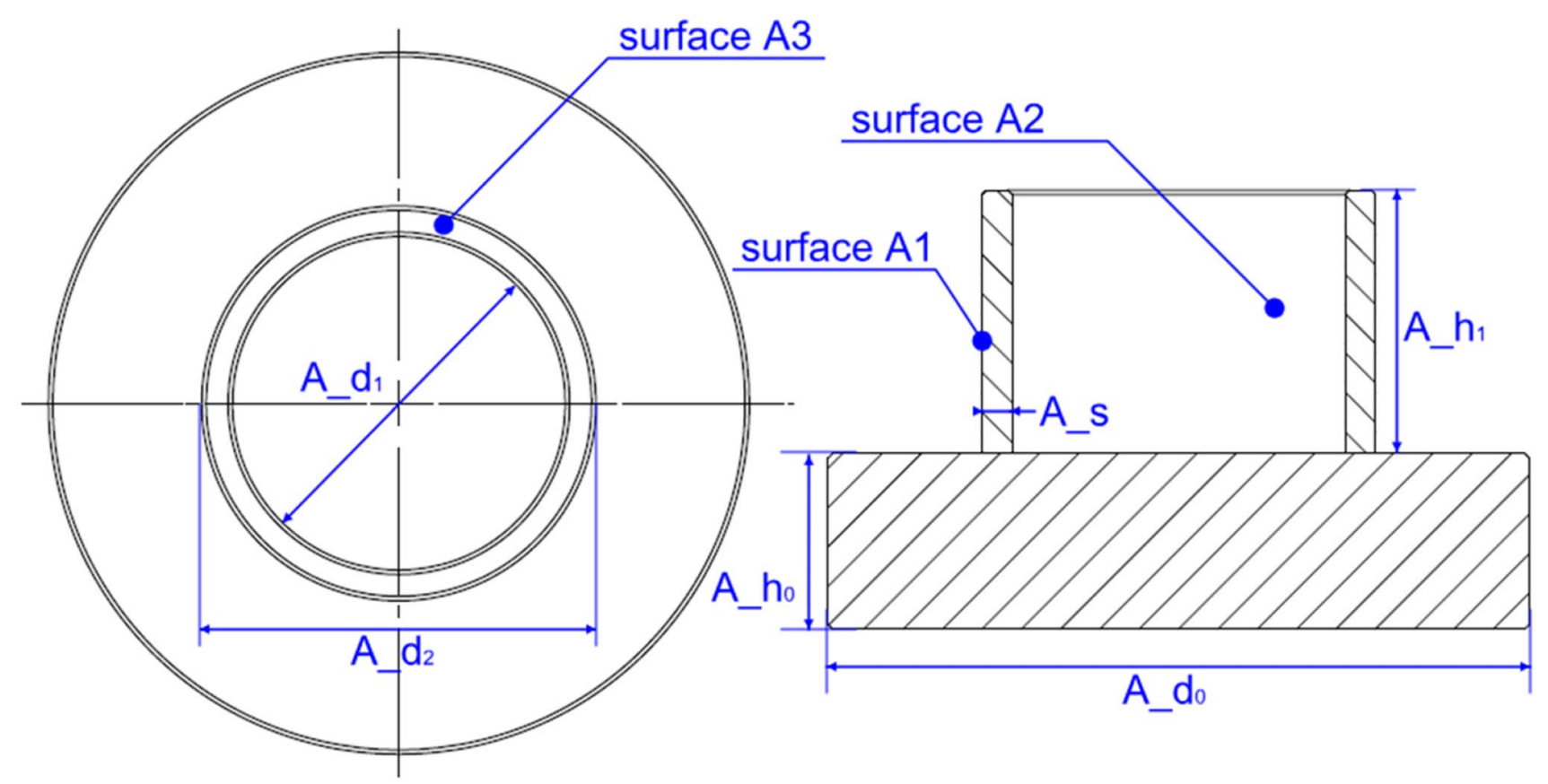

Fig. 1 Geometry of the sample; A_d $0=80 \mathrm{~mm} ; \mathrm{A} \_\mathrm{h}_{0}=20 \mathrm{~mm} ; \mathrm{A} \_\mathrm{d}_{1}=40 \mathrm{~mm} ; \mathrm{A} \_\mathrm{h}_{1}=37 \mathrm{~mm}$

Table 1 Requirements for the design elements of a sample for the LMWD-process

Dimensions: A_d $\mathrm{d}_{1} ; \mathrm{A} \_\mathrm{d}_{2} ; \mathrm{A} \_\mathrm{h}_{1}$; A_s For checking the dimensional accuracy of component features generated by the individual manufacturing steps (processes)

Surfaces: A1; A2; A3

To check the procedure regarding coaxiality, parallelism, flatness, cylindrical shape, and squareness For distortion analysis and investigation of surface roughness (additive, heat treated, post-processing) To investigate the mechanical properties in the surface layer: additive, thermally treated, reworked

Dimensions: A_d $;$; $\mathrm{A} \_\mathrm{h}_{0}$

Dimensions of the base plate on which the desired geometry is built. This results from the clamping strategy, machining method, and economic efficiency

When clamping the base plate with clamping jaws, and to avoid excessive temperature gradients while printing, a certain distance must be maintained to the edge of the base plate

Cylindrical shape in general:

For the robust testing of varied influencing factors of the additive-subtractive process chain For execution of a location-controlled deposition process (in the future) 


\section{Laser metal wire deposition (LMWD)}

\subsection{Setup}

The LMWD was done with a CoaxPrinter processing head from Precitec with a ring-shaped beam profile and a coaxial wire and a fiber-guided disk laser with a $600 \mu \mathrm{m}$ process fiber. A maximum output power of $8000 \mathrm{~W}$ was used as beam source. LMWD uses laser radiation to melt the material and the filler metal to generate a raised track as shown in Fig. 2. The laser radiation is absorbed by the base material, a melt pool is formed, and the wire is guided coaxially to the ring-shaped laser radiation centrally into the melt pool. Experiments, conducted especially for this article, indicate that this rotation-symmetric layout enables a uniform exposure of the melt pool and a central and direction-independent feeding of the wire for the deposition of the material. 3-dimensional components can be generated by connecting several individual tracks.

\subsection{Execution}

For this investigation, the cylindrical samples produced with constant process parameters and with a closed-loop control of the track height were compared. The production parameters were adapted to produce the cylinders as thin walled as possible with a high surface quality to maximise material utilisation for the post-processing. The cylinders were fabricated with a programmed diameter of $40 \mathrm{~mm}$ and a fixed number of layers up to a height of about $37 \mathrm{~mm}$. The programmed path forms a helix which was created with two different axis combinations.

To determine the optimal parameters to produce the cylinders the track speed of the system and the wire feed velocity was kept constant at $2 \mathrm{~m} / \mathrm{min}$ for the feed rate and $4 \mathrm{~m} /$ min for the wire speed. In previous test series, these parameters proved to be functional in the selected power range of approx. 2 to $4 \mathrm{~kW}$ and a beam diameter of 2.5 to $3 \mathrm{~mm}$. To avoid the heat accumulation from the continuous addition of heat to the work piece, which leads to local overheating and therefore unstable process conditions, it is necessary to continuously reduce the laser power. The heat accumulation is mainly caused by the changing heat dissipation over the height during the printing process and leads to deviations in the dimensional accuracy, e.g. for the cylinder shape shown here. This leads to changes in the diameter as well as in the height of the printed components. Due to the novelty of the process, experiments had to be conducted to find the correct parameters. The experiments have shown that at constant laser power $(>3 \mathrm{~kW})$, the build-up of the cylinder failed from a certain height.

Therefore, the power was adapted along the deposited height. Previously, a sequence was developed in a few iterations. After each failed build-up cycle the power was reduced earlier in the sequence. In the final sequence, which was used to produce the cylinders for this work, the power was kept constant at $3300 \mathrm{~W}$ for the first 10 layers (height $5.2 \mathrm{~mm}$ ) and then reduced linearly until the 40th layer (height $20.8 \mathrm{~mm}$ ) to $1980 \mathrm{~W}$. The power was kept then constant for the remaining layers up to the programmed height
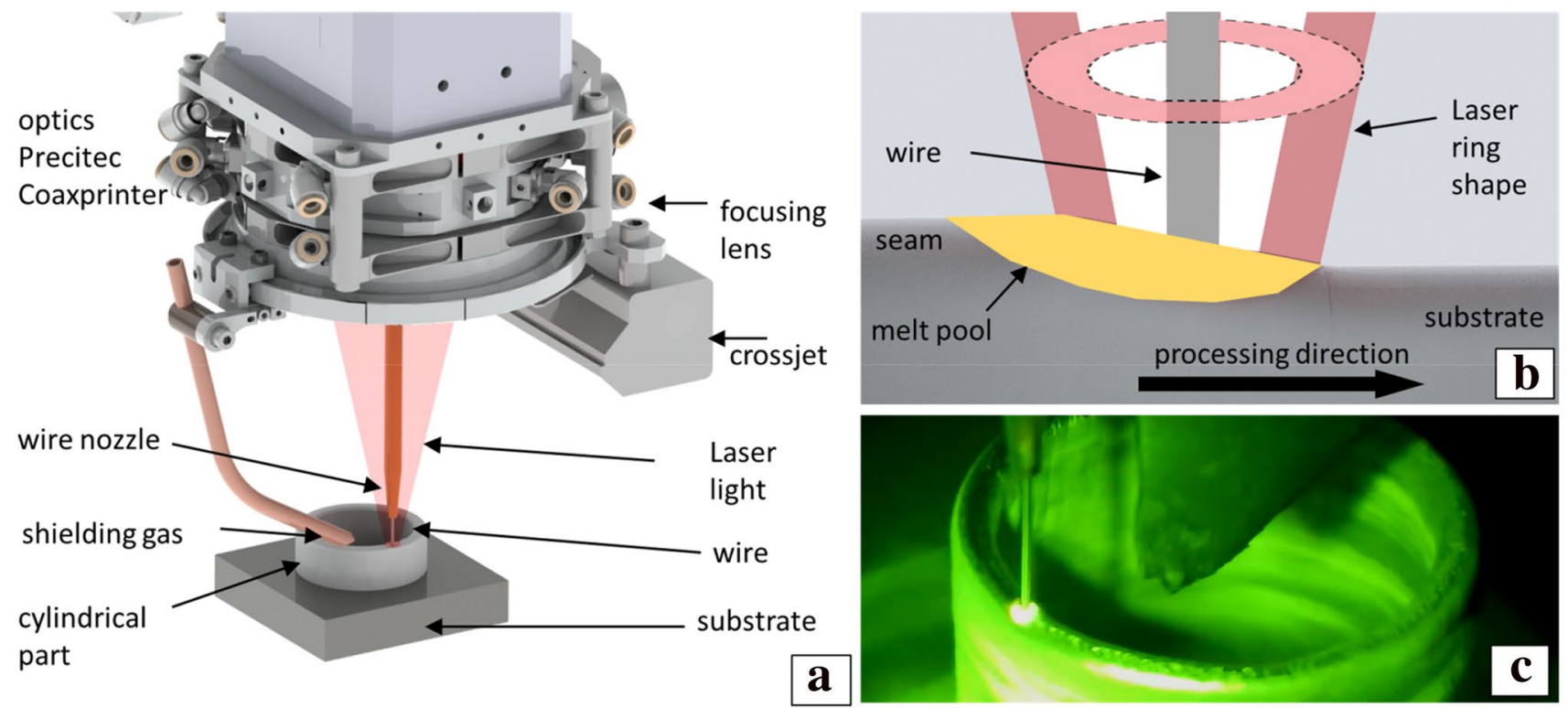

Fig. 2 LMWD-process: a processing head; b laser ring shape and wire; $\mathbf{c}$ deposition process 
of $37 \mathrm{~mm}$. This resulted in the process not failing and a reproducible process.

To keep the wall thickness as minimal as possible for a given wire diameter and to produce the cylindrical shape as uniformly as possible, a small beam diameter $(2.5 \mathrm{~mm})$ was selected. Due to the smaller distance to the focus, the process is much more sensitive to distance changes. If the wire hits the beam in the focus it melts instantly in the air and builds a drop shape. This was observed by an off-axis camera next to the processing head. As shown in Fig. 3 the beam is fully blocked by the wire in drop shape. This keeps the wire away from the melt pool and causes a collapse of the deposition process.

With constant process parameters, local deviations of the track height occur during the running deposition process. These deviations increase from layer to layer. This in turn leads to an uneven height over the circumference of the cylinder. To compensate the height deviations a closedloop control of the track height was implemented. The track height is significantly influenced by the track feed and the wire feeding speed. In this study the track feed was used to control the track height. The feedback signal was generated with a coaxial OCT (optical coherence tomography) based distance measurement (specs of the OCT are shown in Table 2). In this paper we present a closed-loop control with a coaxial OCT distance sensor to measure the track height as input signal and the wire feed rate as controlled variable. The wire feed rate was chosen as control variable due to the

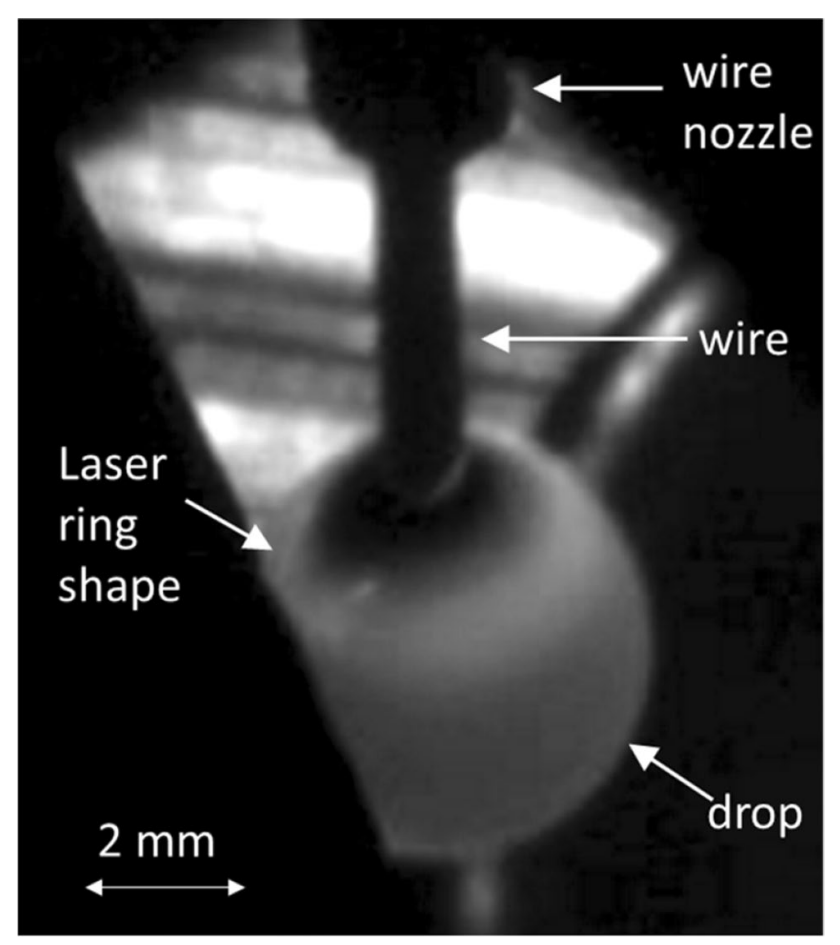

Fig. 3 Melted wire as drop shape
Table 2 Parameters of the AM-process and the OCT

\begin{tabular}{ll}
\hline Laser power & Variable range: 1.4-3.8 kW \\
Fiber diameter & $600 \mu \mathrm{m}$ \\
Wavelength & $1030 \mathrm{~nm}$ \\
Track speed & $2 \mathrm{~m} / \mathrm{min}$ \\
Wire speed & $4 \mathrm{~m} / \mathrm{min} /$ controlled: variable \\
Beam diameter & $2-3 \mathrm{~mm}$ \\
Shielding gas & Nitrogen (20 1/min) \\
Programmed track height & $0.52 \mathrm{~mm}$ \\
Programmed cylinder height & $37 \mathrm{~mm}$ \\
Programmed cylinder diameter & $40 \mathrm{~mm}$ \\
Wire material and diameter & $1 \mathrm{~mm} \mathrm{AlMg5Cr}(\mathrm{S} \mathrm{Al} \mathrm{5356)}$ \\
Substrate material & AlSilMgMn (6082) \\
Proportional factor Kp & 0.39 \\
Integral factor KI & 0.01 \\
OCT device & $\mathrm{CHRocodile2} \mathrm{(Precitec)}$ \\
OCT wavelength & $1550 \mathrm{~nm}$ \\
OCT sample rate & $20 \mathrm{kHz}$ \\
\hline
\end{tabular}

higher dynamics of the wire conveyor compared to the track feed rate. By changing the wire feeding speed, the applied volume per time, and thus the height of the track, can be influenced. The OCT system consists of a super luminescence diode as illumination source, an interferometer setup and a spectrometer to detect the interference; thereby, the OCT device calculates the difference between a reference and the melt pool distance. The OCT beam measurement spot was adjusted laterally to the wire as shown in Fig. 4. Due to the static, lateral measurement, the samples with closed-loop control were produced with a rotated workpiece on a rotational axis instead of moving the processing head

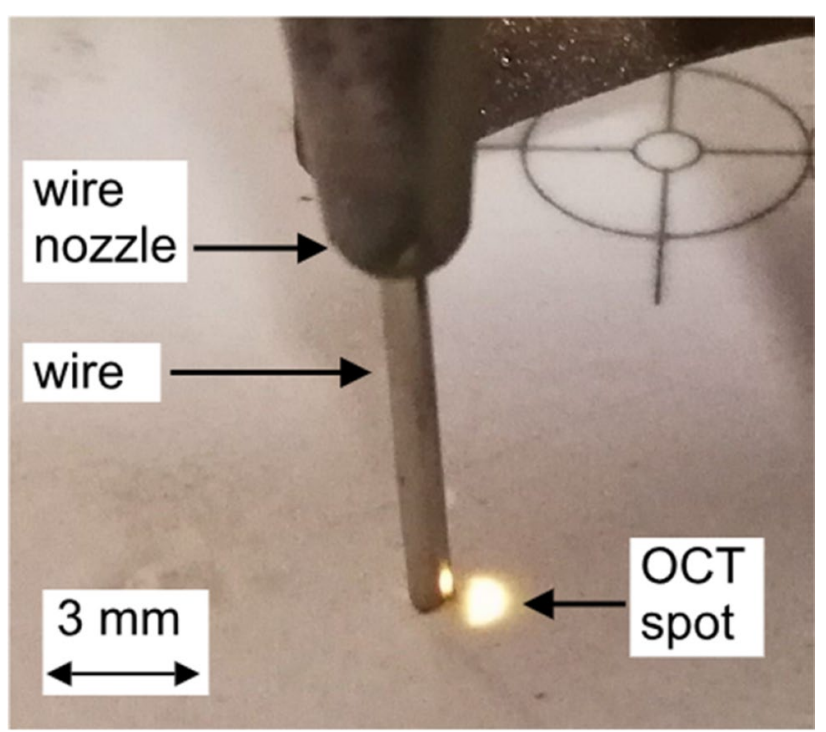

Fig. 4 OCT-measuring spot on conversion card 
to ensure the same orientation of the measurement spot to the weld path.

The measurement signal of the CHRocodile 2 from Precitec was fed directly to the machine control system and used for the controller concept shown in Fig. 5. The reference signal $r(t)$ (the track height) respectively the distance between optic and work piece was generated from the CNC program. The reference error $\mathrm{e}(\mathrm{t})$ is defined as the difference between reference signal $r(t)$ and the measured output signal of the track height $\mathrm{y}(\mathrm{t})$. The output of the controller and the input to the system (the deposition process) are the wire feed rate $\mathrm{u}(\mathrm{t})$ and the disturbance $\mathrm{w}(\mathrm{t})$.

As controller a simple PI-controller was used because of its simplicity and the robustness. The transfer-function

$u(t)=K_{p} \cdot e(t)+K_{I} \int_{0}^{t} e(\tau) d \tau$

in its parallel structure as shown as a standard control loop was taken from [14]. With $K_{p}$ as the proportional factor, $K_{I}$ the Integral factor and $e(t)$ is the reference error dependant on time $t$ with $\tau$ as the time constant. The control factors $K_{p}$ and $K_{I}$ were calculated in Matlab with the method of step response analysis and are optimised experimentally. In addition to the OCT measurement a pyrometer was integrated to monitor the process. The laser power was adjusted manually using the pyrometer signal as reference to avoid an overheating of the process. A crossjet was arranged on the side to protect the optics as well as a shielding gas nozzle to avoid oxidation.

The following process parameters were used for the sample production (Table 2):

\subsection{Results}

Table 3 shows the samples produced as well as their classification after the used range of laser power.

Figure 6 shows typical examples of the produced cylindrical samples without control (Fig. 6a), with control A (Fig. 6b) und control B (Fig. 6c). It was found that the outer and inner sample diameters differ significantly depending on the type of process control. It was found that the outer and inner sample diameters differ significantly depending on the type of process control.

Figure 7 shows the measured radii along the sample wall for three different samples. The upper part of the sample shows the end of the process, where the last line of wire was deposited. Irrespective of whether the LMWD process was carried out in an uncontrolled or controlled manner, the wall thicknesses in the lower sample area are predominantly smaller than in the upper area (not regarding the end of the process). This can be explained by a heat flow that

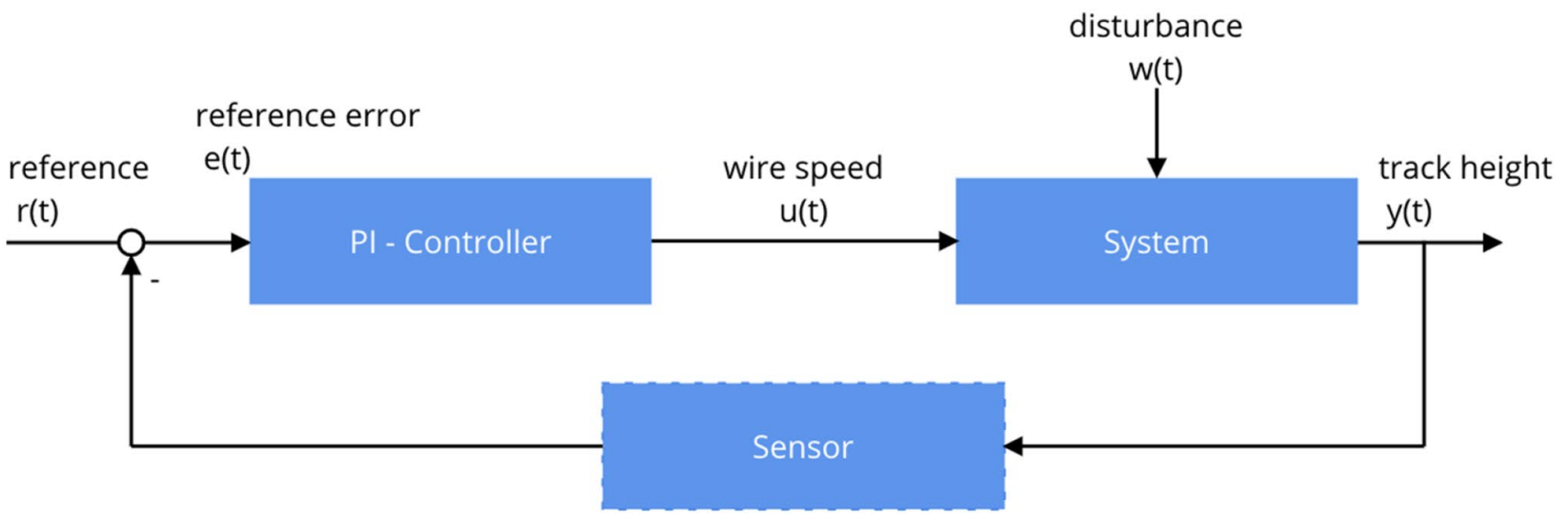

Fig. 5 Block diagram of a closed-loop control system

Table 3 Classification of the processes used to fabricate the samples and their produced numbers

\begin{tabular}{llc}
\hline Process classification & $\begin{array}{c}\text { Range of laser power (W) } \\
\begin{array}{l}\text { Number of } \\
\text { samples pro- } \\
\text { duced }\end{array}\end{array}$ & 7 \\
\hline Process parameter without closed-loop control of the track height (without control) & $3800-2800$ & 6 \\
Process parameter with closed-loop control of the track height (control A) & $3200-1900$ & 6 \\
Process parameter with closed-loop control of the track height (control B) & $2500-1450$ & 6 \\
\hline
\end{tabular}




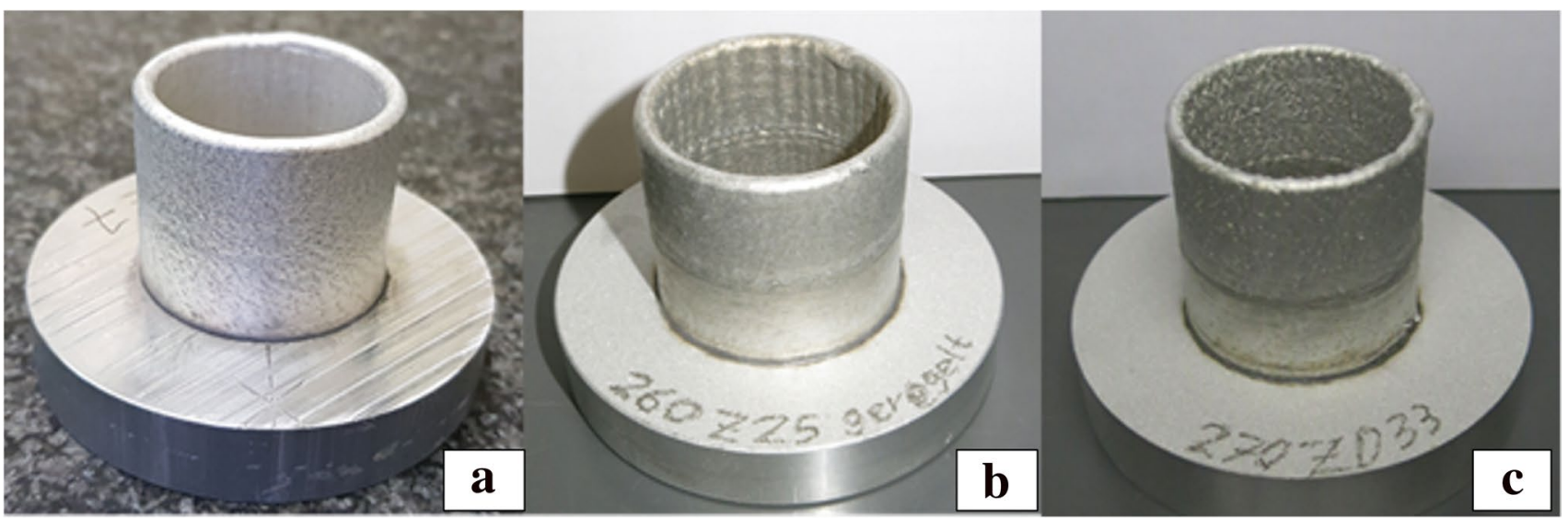

Fig. 6 Results of the LMWD-process: a without control; $\mathbf{b}$ with control A; $\mathbf{c}$ with control B
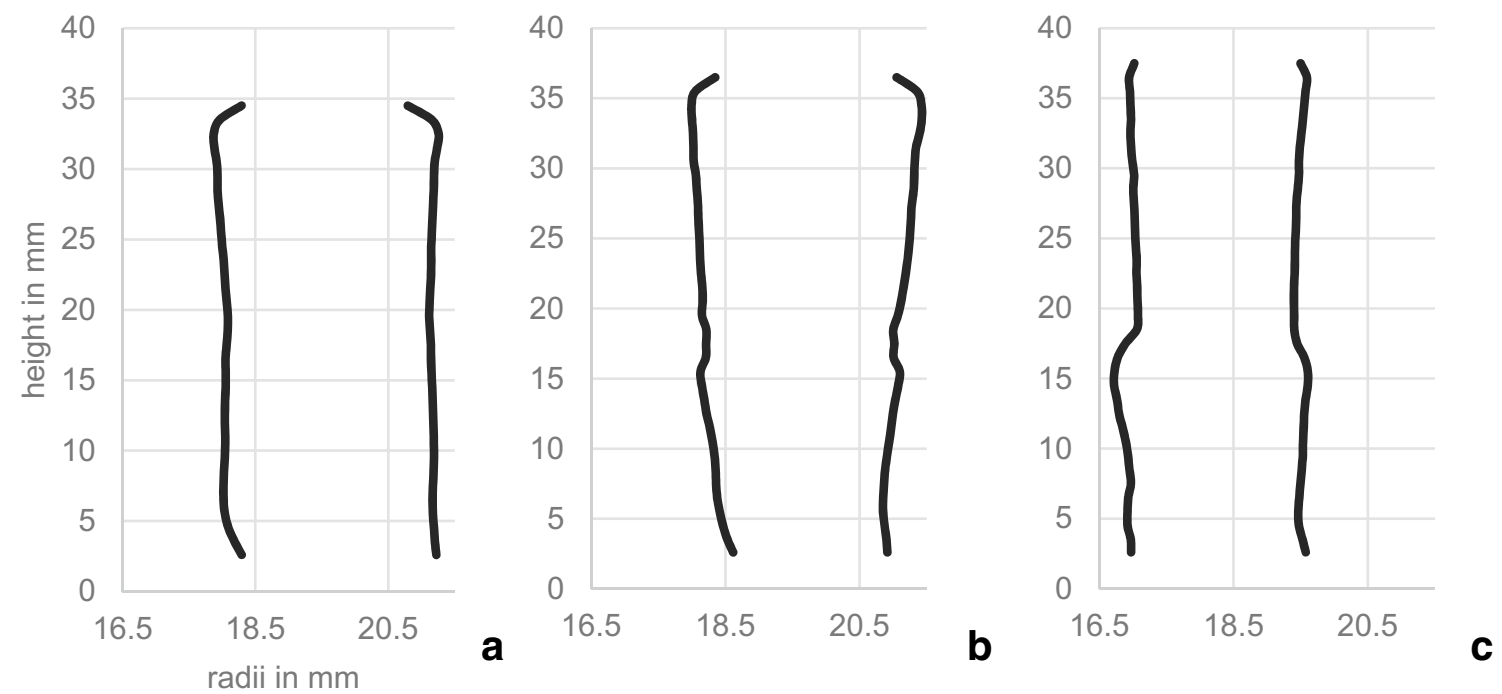

Fig. 7 Wall thickness or outer and inner radii. Exemplary representation: a process without control; b control A; c control B

changes with increasing component height. After a rapid heat flow into the building platform at the beginning of the LMWD process, this flow slows down with increasing height of the generated ring cross-section. In connection with the decreasing heat flow, the heat conduction losses are smaller and lead to a wider melt pool with higher temperatures. Shortly before the end of the process, the wall thickness thus reaches its highest values. The components thus tend to have a generally conical shape. A comparison of the component height shows that in the process without control the maximum height reached is $35 \mathrm{~mm}$, in the controlled processes $36.6 \mathrm{~mm}$ (process control A) and $37.5 \mathrm{~mm}$ (process control B).

The wall thickness of the cylinder from the process without control is relatively homogeneous and "wide" in the height segments from 5 to approx. $30 \mathrm{~mm}$. In contrast, the cylinders from the controlled processes are "narrow" at the beginning of the additive process but increase with the cylinder height (especially in controlled process A). To reduce the wall thickness, the laser power was reduced in both processes at a height of approx. 15-20 $\mathrm{mm}$. The wall thickness increases because the heat accumulated in the upper part of the samples. This resulted in a wider molten pool and therefore after solidification into thicker walls. This was examined by the off-axis camera while controlling the process. In controlled process $\mathrm{A}$, the laser power fell from 3200 to $1900 \mathrm{~W}$ and remained constant until the end of the process (see Fig. 8 for an example sample with control A). This was reflected on the wall thickness of the component as a short thinning at a height of $16-18 \mathrm{~mm}$, then the wall thickness of the component rise and reaches the maximum size shortly before the end of the process (see Fig. 7b) and 


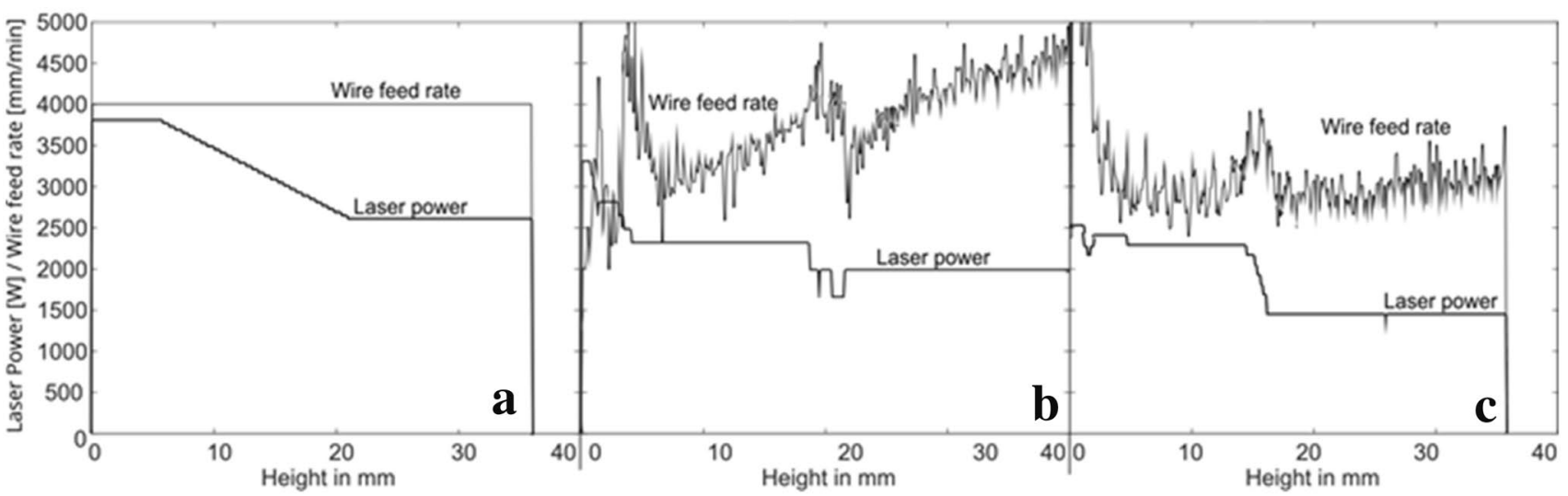

Fig. 8 Laser power and wire speed: a without control; $\mathbf{b}$ with control A; $\mathbf{c}$ with control B

the corresponding measurement data in Fig. 8b. In controlled process $\mathrm{B}$, the laser power was reduced much more strongly from $2500 \mathrm{~W}$ to approx. $1450 \mathrm{~W}$ as seen in Fig. 8c. As a result, the wall thickness of the component dropped in the $16-18 \mathrm{~mm}$ height range and remained relatively constant until the end of the process (see Fig. 7c).

As shown in Fig. 8, the laser power and the wire speed of the controlled and uncontrolled process is different. As discussed previously, it was necessary to reduce the power to avoid overheating of the work piece. In samples without control this was done automatically by the machine over the height. In the processes with control (A and B) because of the smaller spot size and the thinner wall the process was more unstable, and the power adjustment was done manually. As shown in process A the height control influences the wire speed. The power was reduced to $1900 \mathrm{~W}$ after a short period of time. Over the rising height, the wire speed was also increasing. As shown in process B the wire speed is much more constant at $3000 \mathrm{~mm} / \mathrm{min}$ because the power was reduced to $1450 \mathrm{~W}$. This could be explained because of less heat accumulation due to the lower overall used laser power.

Based on the axial measurements of the outer and inner diameters, the wall thicknesses were determined for a smooth cylinder with maximal dimensions (for optimal material utilization) for all manufactured components, as shown in Fig. 9. On the bar chart Fig. 9 the wall thickness was shown as the average value, maximum and minimum taken from all samples. The wall thickness results from the difference between the outer and inner radius. For each component, the outer radius was assumed to be the minimum of the diameter and/or radius measurements on the sample and the inner radius was assumed to be the maximum. Thus,
Fig. 9 Wall thickness of fitted cylinder with maximal dimensions

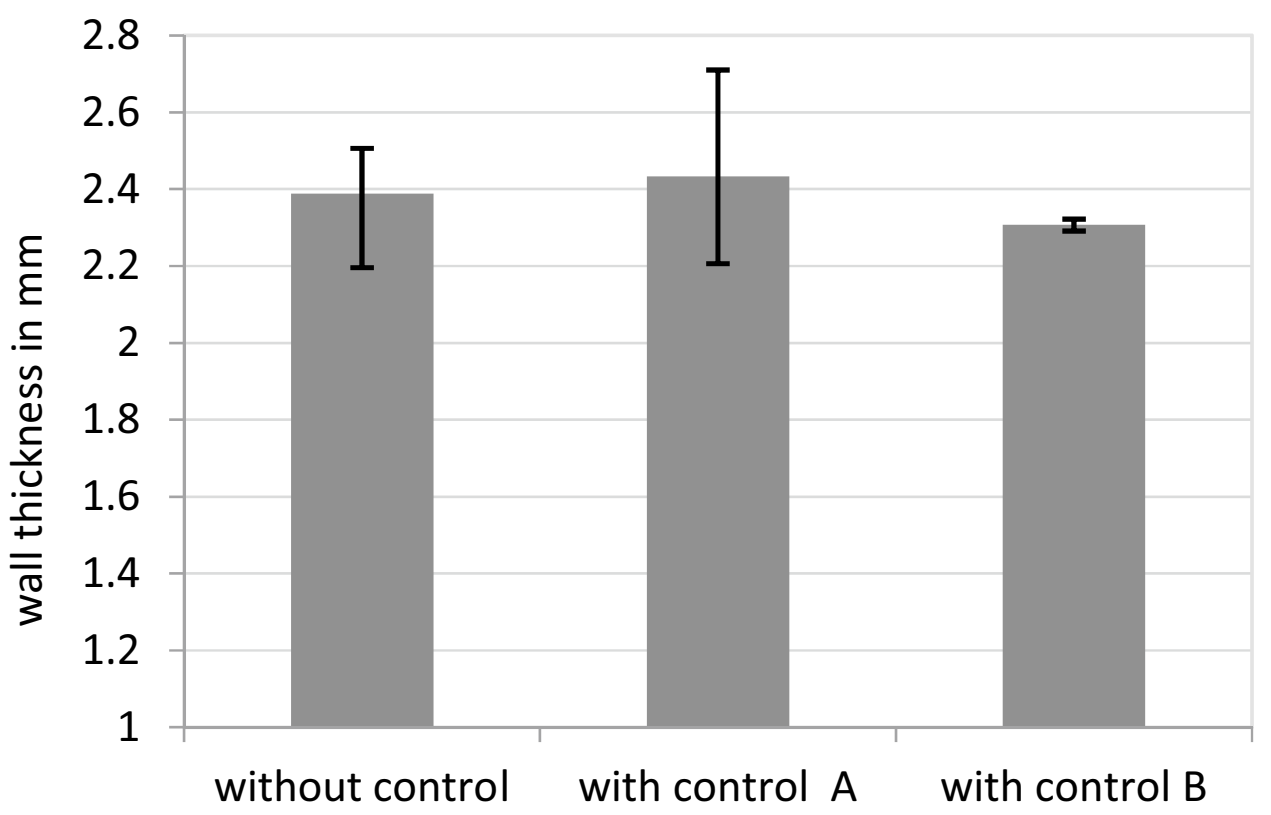


the maximum wall thickness of the cylinder element was defined, and the cylinder volume calculated according to Eqs. (2-3), as pointed out later in 0 .

The 3D surface measurements on the samples upper side surface $\mathrm{A} 3$ were performed by an autofocus measuring device of the type InfiniteFocus $\mathrm{G}$ from Alicona Imaging $\mathrm{GmbH}$. The measurement parameters were: Magnification: $\times 5$; measuring field: $2.814 \mathrm{~mm} \times 2.814 \mathrm{~mm}$; Number of measuring points: $1600 \times 1600$; exposure time $6.077 \mathrm{~ms}$. A top view of the samples in Fig. 10 shows a significant influence of the process control on the height distribution at the top of the samples. For the samples taken from the process without control, the highest points (relative to the zero level of the topmost application web) were in the range $0.6-0.8 \mathrm{~mm}$ higher than the average height of the cylinder; for the components from controlled process $\mathrm{A}$, these were in the range $0.5-0.6 \mathrm{~mm}$, and for controlled process $\mathrm{B}$, in the range $0.4-0.5 \mathrm{~mm}$. It should be noted that the components from the process without control have two distinct raised areas (in red) and one strongly recessed area (in blue). These differences in height are caused by process variations in the track height which are additionally increased by the heating of the component. For the components from the controlled process no pronounced local minima in height were found, the area with the maximum height was at the end point of the LMWD process for all components.

Subsequently, the 2D roughness of the test components was examined tactilely with the measuring device "Formtracer SV-C3200". The focus of the investigations was the determination of the characteristic values $\mathrm{Ra}$ and $\mathrm{Rz}$ for the evaluation of the surface quality of the components. The arithmetic mean Ra is the average of the absolute values along the individual measuring section. The maximum height of the profile $\mathrm{Rz}$ is the absolute vertical distance between the maximum height and the maximum depth of the profile along the individual test section [15]. The inspection of the surface quality of the surfaces A1 and A2 according to Fig. 1 was carried out. The measuring tip radius was $2 \mu \mathrm{m}$ and the measuring path length $4 \mathrm{~mm}$.

From Fig. 11 it becomes clear that the Ra and Rz values on the outside and inside differ considerably. The Ra and $\mathrm{Rz}$ values on the outside of the components from the LMWD process without control and from the controlled process $\mathrm{B}$ are relatively stable. In contrast, the $\mathrm{Ra}$ and $\mathrm{Rz}$ values on the inside of the components increased with the height of the component and reached maximum $\mathrm{Ra} / \mathrm{Rz}$ values of $10.67 \mu \mathrm{m} / 53.59 \mu \mathrm{m}$ (controlled process B) and $5.72 \mu \mathrm{m} / 49.73 \mu \mathrm{m}$ (uncontrolled process). These differences can be explained by the specific heat conduction in the partially closed space of the additive-manufactured component, which result in thermally induced tensions. The heat dissipation is more advantageous on the outside than on the inside, because on the outside the environment helps to dissipate the heat, whereas in the inside the heat builds up. Overall, the highest roughness values were determined for the samples from controlled process B on the inside. It can thus be concluded that the strong reduction of the laser power in the process (up to $1450 \mathrm{~W}$ ) has a negative effect on the surface quality.

For components from the controlled process A, the lowest and even decreasing Ra values were found on the outside. This can be attributed to the distinct conical shape of the component wall, see Fig. 7. The small reduction of the laser power to $1900 \mathrm{~W}$ resulted in higher roughness values on the inside of the component.

In summary, it can be concluded that the process execution (process control) has a subsequent effect on the component geometry and surface:

- Process without control: lowest (insufficient) part height, good volume homogeneity (small shape deviation), largest wall thickness, good surface quality,
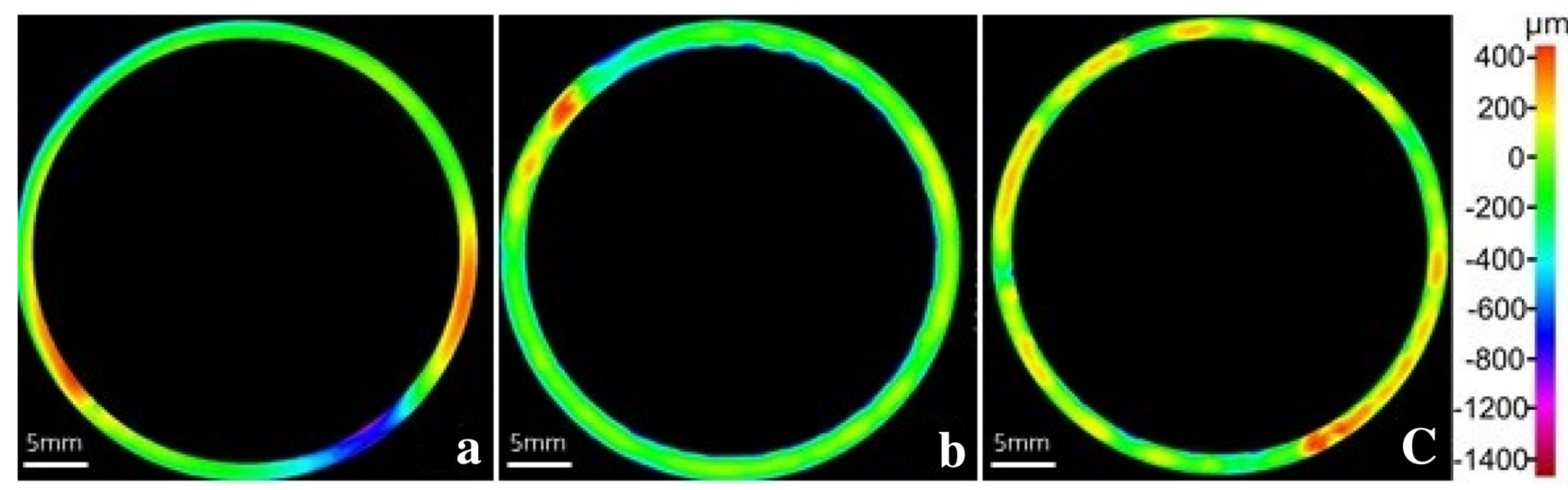

Fig. 10 Typical 3-D surface view of the samples (top view). a LMWD process without control; $\mathbf{b}$ with process control A; $\mathbf{c}$ with process control B 

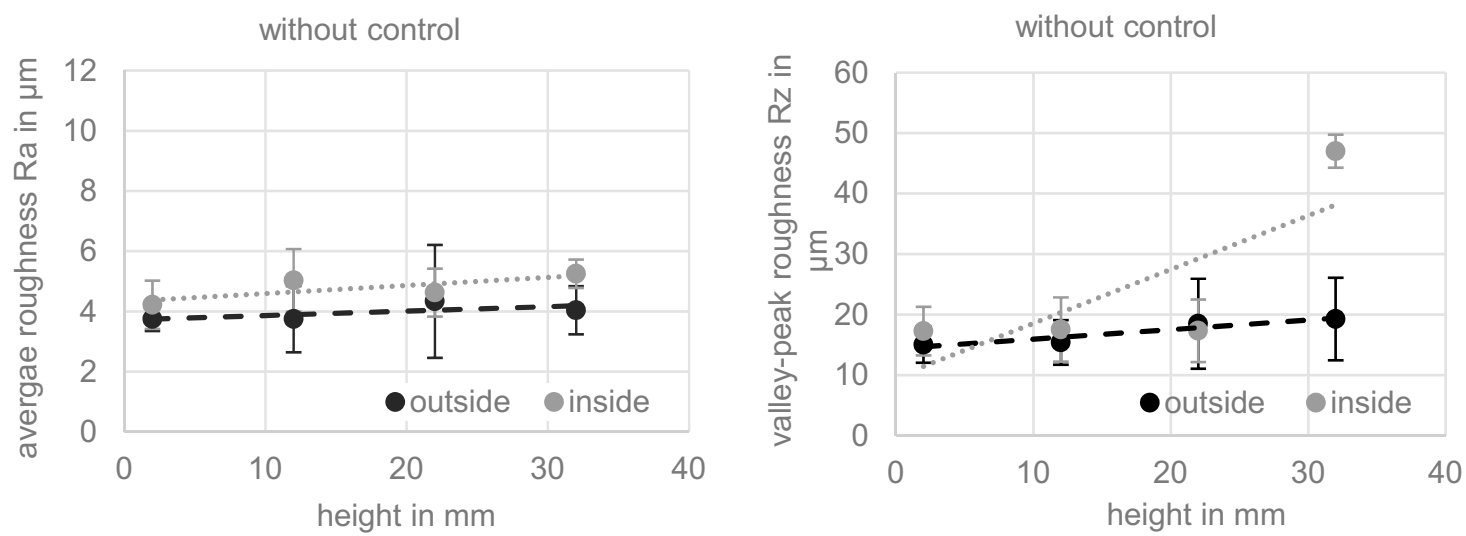

control A

control A
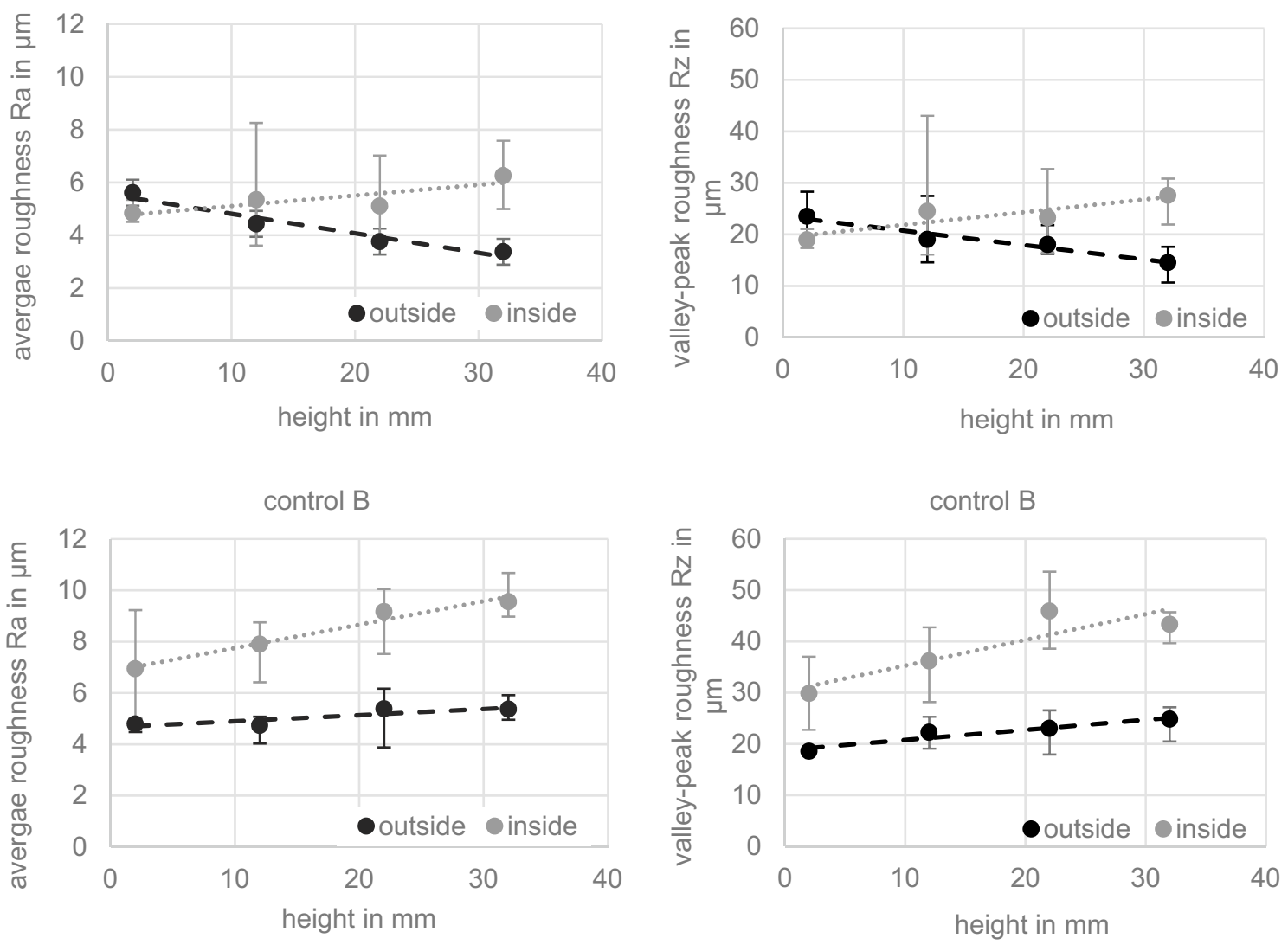

Fig. 11 Roughness characteristics Ra and Rz on the outside and inside of the samples

- Controlled process A: good component height, relatively high-volume inhomogeneity, large wall thickness, best surface quality on the outside of the component,

- Controlled process B: maximum part height, high homogeneity, minimum wall thickness, low surface quality.

\subsection{Evaluation}

The additively manufactured cylindrical part was analysed using a 3D coordinate measuring machine of type MC850 from Carl Zeiss AG using an Ultra High Precision Caliper probe system with a measuring ball radius of $2.5 \mathrm{~mm}$ as shown in Fig. 12a). The measuring strategy for the samples was created with the software "Calypso" to measure the element from the outside and inside with a tactile probe. The geometry of the component was imported in the form of a STEP file and the nominal dimensions of the component were specified by the measuring element "cylinder". The measuring distance along the additive build direction (Z-axis) was $1 \mathrm{~mm}$. Thus, several inner 

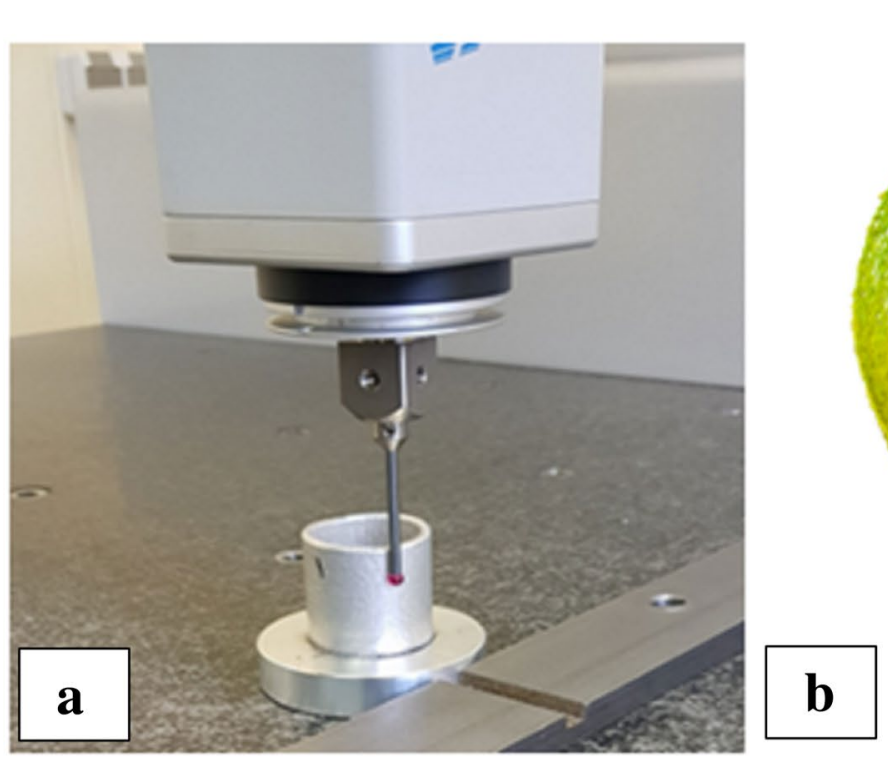

[mm]

Fig. 12 a Measurement system Zeiss MC850; b typical evaluation of the sample

and outer diameters of the samples were measured with an accuracy of $0.1 \%$ relative deviation. The outer and inner diameters/radii as well as the roundness of the cylinder were evaluated as shown in Fig. 12b).

Based on the evaluated results, the actual volume of the additively manufactured cylinders

$V_{\text {actual } \text {,sample }}=\sum_{i=1}^{n} \pi\left(R_{i, \text { outside }}^{2}-R_{i, \text { inside }}^{2}\right) * \Delta h_{i}$

was calculated using the incremental measured outer radius $R_{i, \text { outside }}$ and inner radius $R_{i \text {,inside }} a$ t each increment $i$ with the incremental height $\Delta h_{i}$. This additive volume $V_{\text {actual,sample }}$ was then compared with the volume of a "best-fit" cylinder

$V_{\text {bestfit,sample }}=\pi\left(R_{\min , \text { outside }}^{2}-R_{\max , \text { inside }}^{2}\right) * A \_h_{1, \text { sample }}$

Using the minimal outer radius $R_{\text {min,outside }}^{2}$ and maximal inner radius $R_{\text {max, inside }}^{2}$ of the measurement increments for each sample and the actual sample height $A \_h_{1, \text { sample }}$. The volume which must be removed to achieve the final shape of the cylinder

$V_{\text {removal,sample }}=V_{\text {actual,sample }}-V_{\text {bestfit,sample }}$

was then calculated as the difference between the volume of the additive produced cylinder $V_{\text {actual }}$ and the best-fit volume as shown in Fig. 13.

\section{Subtractive machining}

\subsection{Setup}

To produce the desired cylindrical nominal contour on the additively manufactured samples, these were subsequently machined. The required external and internal longitudinal turning was carried out on an R200 turning/milling center from INDEX-Werke GmbH \& Co. KG. using water-based flood cooling lubrication (Blasocut BC 935 Kombi) as shown on the left side in Fig. 14. The tools used for internal and external longitudinal turning are shown on the right side in Fig. 14. The machining parameters were taken from the Technical Manual for Turning, Parting and Threading [16]. They are listed in Table 5. It should be noted that the values for both internal and external turning on the respective heights are the same, as can be seen in Fig. 15.

The insert geometry is listed in Table 4. For further information we would like to refer to the website of the Walter AG under [17].

\subsection{Results}

With a view to achieving the highest possible efficiency of the overall process, the volume of material to be used in 
Fig. 13 Necessary material removal after the LMWDprocess

Fig. 14 a External turning process; $\mathbf{b}$ tool used for internal turning
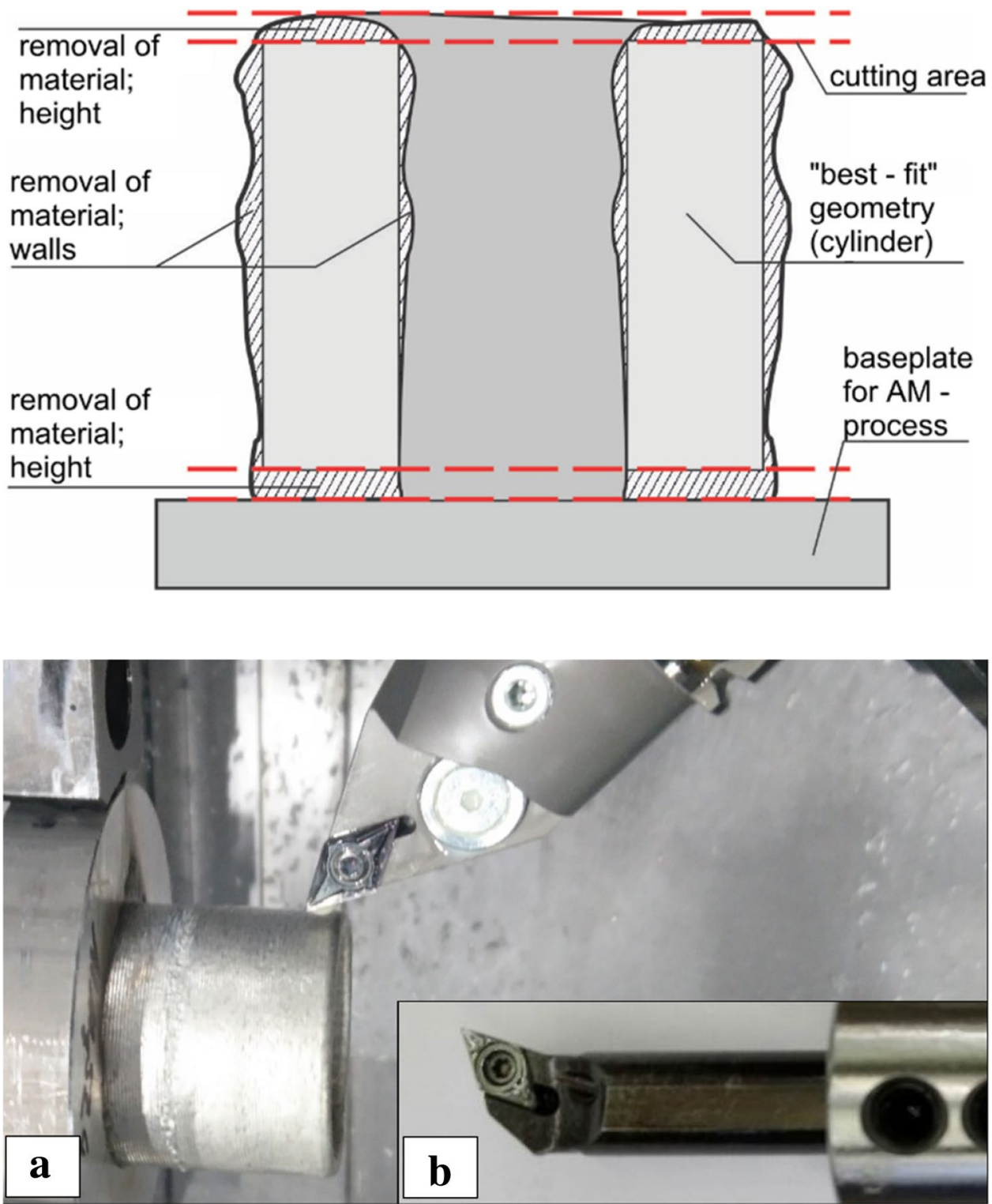

the additive production phase should be as high as necessary and the volume of material to be removed should be kept as low as possible in the subtractive machining phase. However, a minimum allowance is required to guarantee a stable machining process and to be able to compensate for the form errors that occur after the LMWD process. The maximum dimensions of an ideal cylinder for the samples (best possible cylindricity of the lateral surfaces and parallelism on the top/bottom sides) were derived from the measurements carried out in Sect. 2, see Fig. 7. The minimum outer radii and maximum inner radii of the additively produced part (without foundation) were used as a reference to achieve maximum utilisation of the material.

Figure 16 shows the calculated volume of material to be removed. With a process control in the LMWD process, the volume to be machined later can be significantly reduced. The lowest required removal of $9.67 \%$ could be determined for components produced with the controlled process $B$. The process without control requires the most material removal, because the minimal wall thickness, as defined in the goals of this investigation, has to be reached, as shown in Fig. 13.

Since control B has the best material utilization, we will limit all further investigations to process B and leave height process A out of consideration.

The material removal along the cylinder jacket was achieved by a turning process with a cutting speed $v_{c}$ and feed rates $f_{1}$ and $f_{2}$ (see Table 5). First the outside, then the inside of the generatively manufactured component (Fig. 5) was machined. Then the upper side of the component was face-turned (removal of $1 \mathrm{~mm}$ from the uppermost point of the component) and finally detached from the foundation 


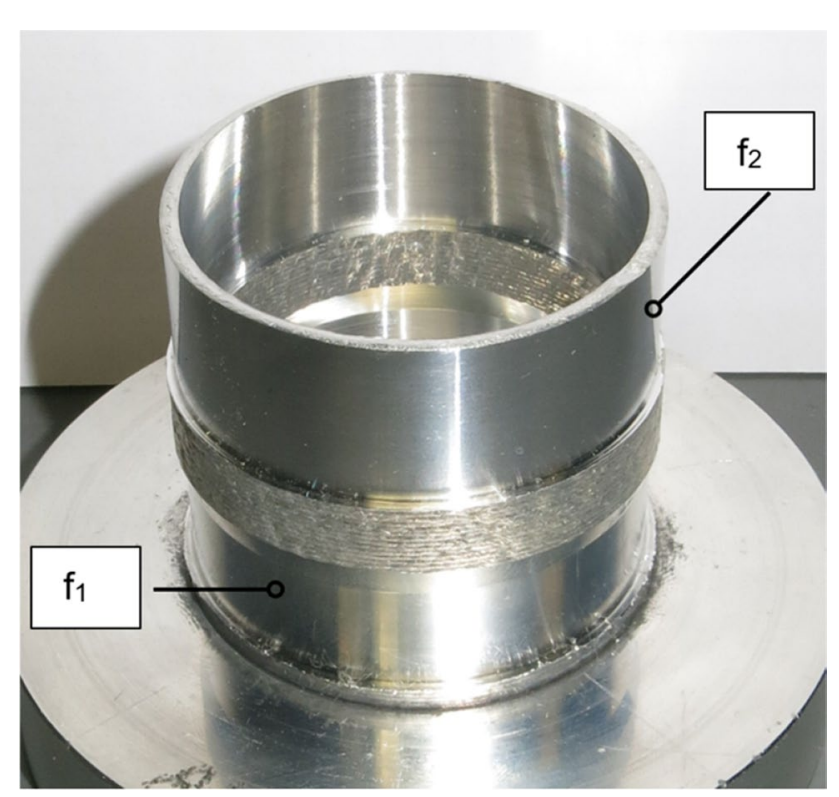

Fig. 15 Test component after the turning process with the respective feed rates used (feed rate used on the inside is equal to the outside)

Table 4 Insert geometry data

\begin{tabular}{lll}
\hline & External turning & Internal turning \\
\hline Designation & DCGT11T304-FN2 & DCGT070204- \\
& WNN10 & MN2 \\
& & WNN10 \\
Material & Carbide & Carbide \\
Geometry & Rhombic 55 & Rhombic 55 \\
Length 1 & $11.63 \mathrm{~mm}$ & $7.75 \mathrm{~mm}$ \\
Radius $\mathrm{r}$ & $0.4 \mathrm{~mm}$ & $0.4 \mathrm{~mm}$ \\
\hline
\end{tabular}

by cutting off. The component lost $3.5 \mathrm{~mm}$ of its height, measured from the foundation, by being cut off.

After the necessary material removal and subsequent cutting off, all samples were qualitatively examined. A comparative evaluation of the component roundness before and after subtractive machining showed a roundness deviation of $R=0.010-0.013 \mu \mathrm{m}$ for $\mathrm{f}_{1}$ and $\mathrm{R}=0.004-0.010 \mu \mathrm{m}$ for $\mathrm{f}_{2}$ with controlled deposition and $\mathrm{R}=0.042-0.045 \mu \mathrm{m}$ for $\mathrm{f}_{1}$ and $\mathrm{R}=0.015-0.018 \mu \mathrm{m}$ for $\mathrm{f}_{2}$ with uncontrolled deposition. Overall, the values of the roundness deviation on the inside of the component after machining turned out to be higher, since the strong inhomogeneities on the inside cannot be completely levelled out by minimal material removal. A typical roundness evaluation is shown in Fig. 17.

Regardless of the nature of component generation in the additive process, the roughness values after machining hardly differ, as shown in Fig. 18. However, as expected, an influence of the machining parameters of subtractive machining could be observed. With the cutting speed $\mathrm{v}_{\mathrm{c}}=500 \mathrm{~m} / \mathrm{min}$ and the feed rate $\mathrm{f}_{1}=0.05 \mathrm{~mm} / \mathrm{rev}$, the average roughness value resulted in $\mathrm{Ra}=0.19 \mu \mathrm{m}$ (outside) and $\mathrm{Ra}=0.4 \mu \mathrm{m}$ (inside). When machining at a feed rate of $\mathrm{f}_{2}=0.1 \mathrm{~mm} / \mathrm{rev}$, smaller Ra and Rz- values were achieved on the inside of the uncontrolled manufactured components. Compared to the components from the controlled process, this can be explained by the need for increased material removal for these samples (Fig. 16). It was possible to reduce the $2 \mathrm{D}$ roughness values of the components from the controlled process with increased material removal. However, this contrasted with the main objective to keep the material removal as low as possible and to limit machining post-processes to a necessary minimum.
Fig. 16 Determined values of the volume to be removed, classification according to parameters of the AM process; maximal, minimal and the average values of all measurements taken are displayed

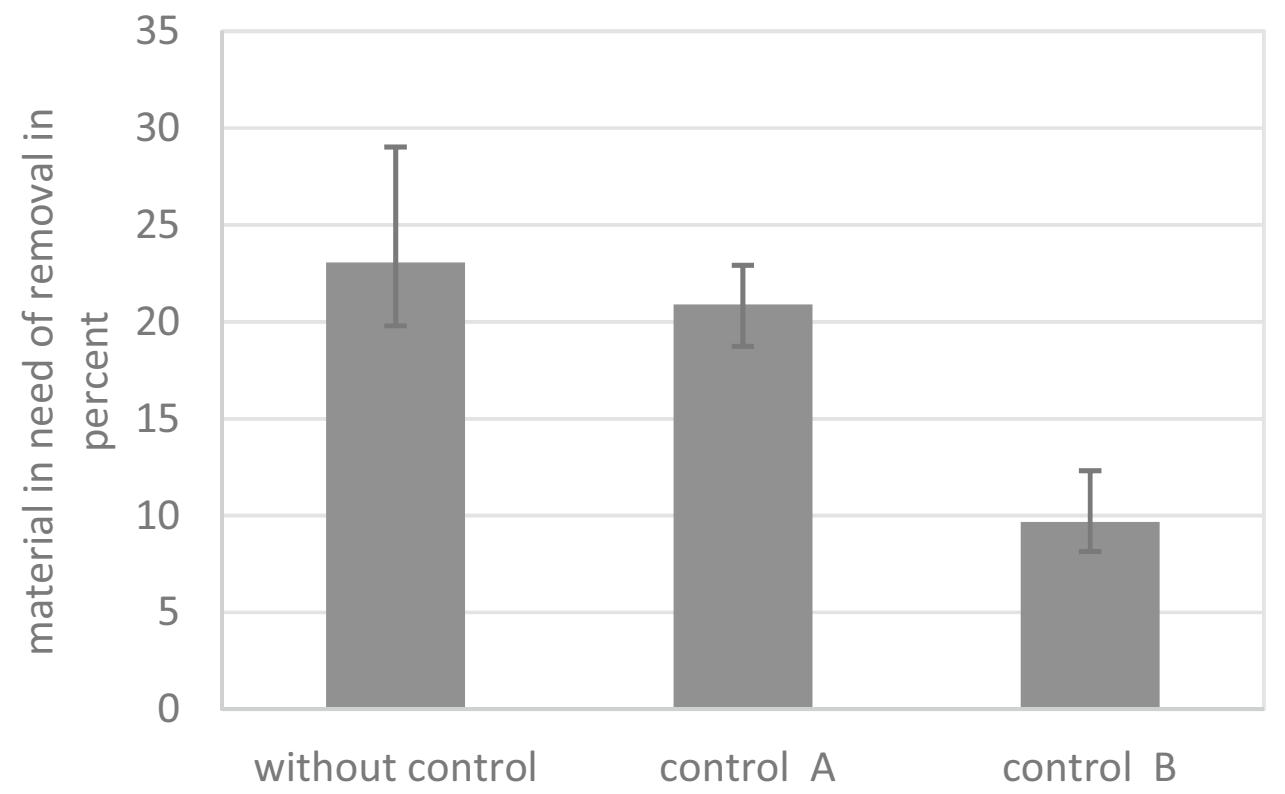


Table 5 Machining parameters for the post-additive turning process

\section{Cutting speed $\mathrm{v}_{\mathrm{c}}$}

Feed rate used on the lower cylinder $\left(f_{1}\right)$

$500 \mathrm{~m} / \mathrm{min}$

Feed rate used on the upper cylinder $\left(\mathrm{f}_{2}\right)$

$0.05 \mathrm{~mm} /$ revolution

$0.1 \mathrm{~mm} /$ revolution

All machining operations were conducted under flood cooling with emulsion
Roughness parameters based on 2D profile measurements allow only limited information about the functional properties of a surface and can at best be applied to periodic (regular) surface structures. Therefore, 3D measurements of the surface microstructure were used to evaluate the functionality of the manufactured surfaces. This should enable a complete characterization regarding sealing, lubrication, friction, and wear behaviour.

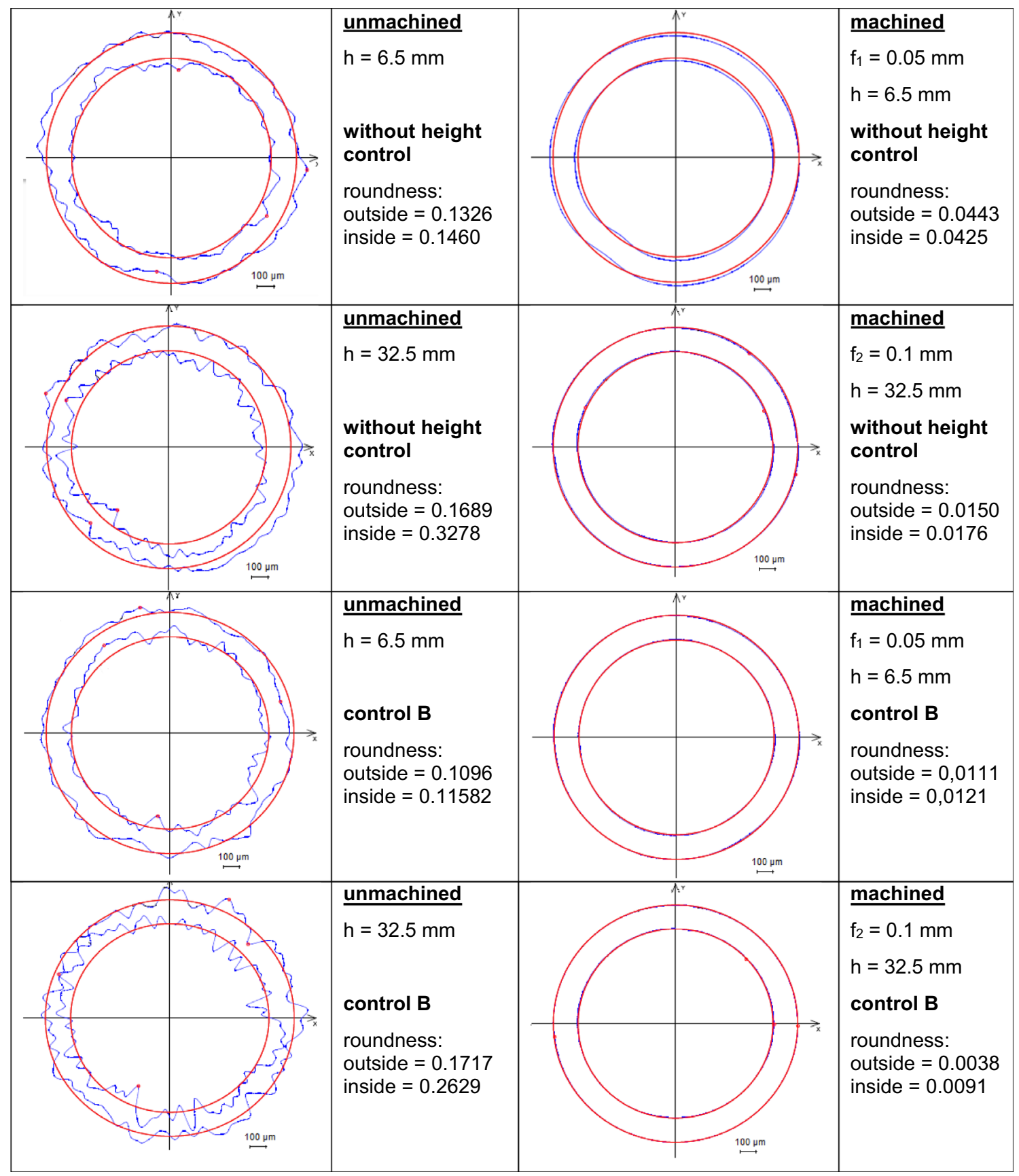

Fig. 17 Roundness after additive manufacturing and after subtractive machining. Process without control (first two rows); with control B (last two rows) 


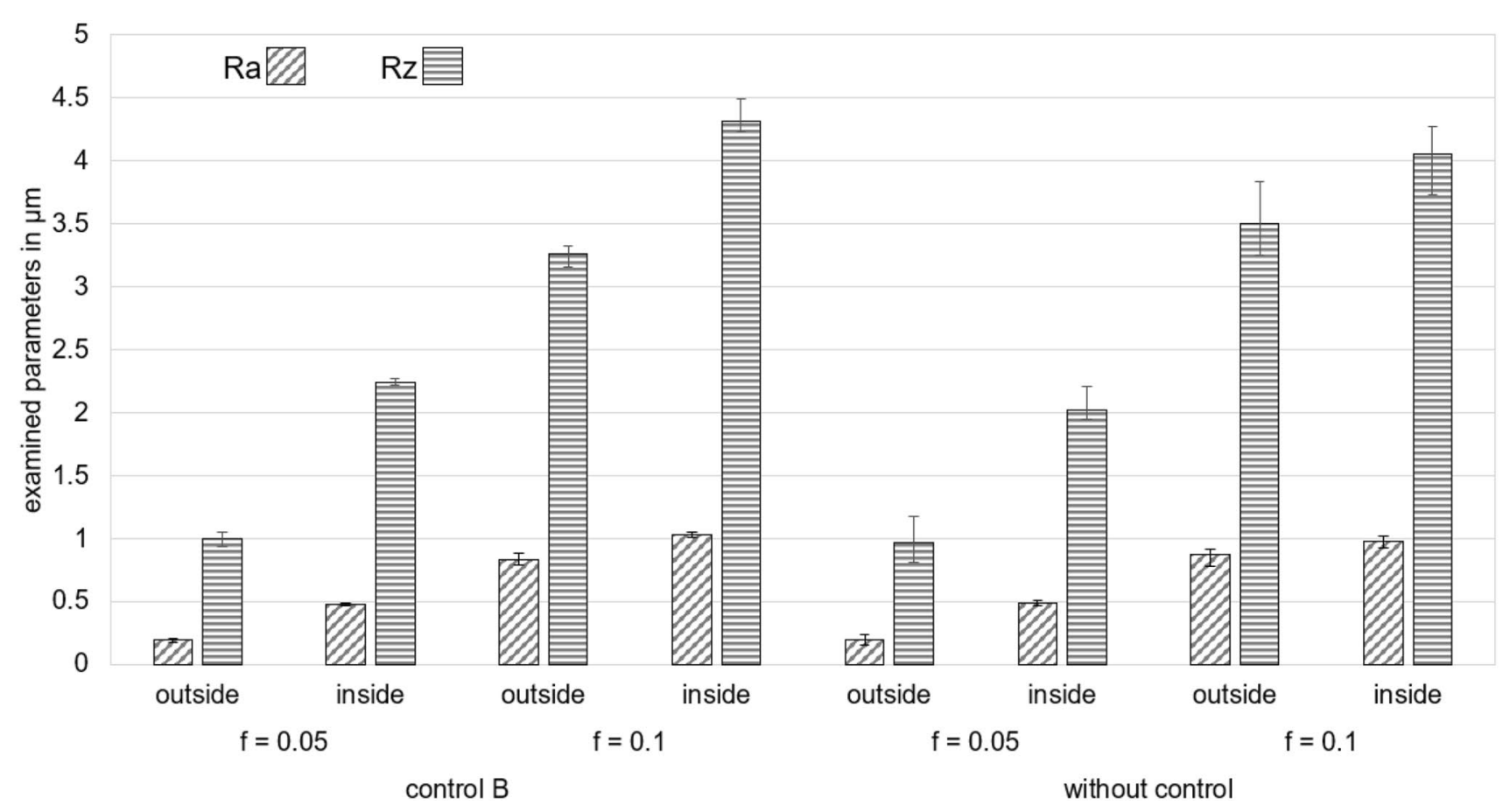

Fig. 18 Average roughness Ra and average roughness depth $\mathrm{Rz}$ on the outer and inner surfaces of different test parts after turning with $\mathrm{v}_{\mathrm{c}}=500 \mathrm{~m} / \mathrm{min} ; \mathrm{f}_{1}=0.05 \mathrm{~mm} / \mathrm{rev}$ and $\mathrm{f}_{2}=0.1 \mathrm{~mm} / \mathrm{rev}$

3D surface parameters are particularly suitable for the evaluation of surfaces, e.g. regarding their suitability for a subsequent coating or their function as sliding surfaces. With respect to coating, the three parameters Sa (average height of selected area), Sp (maximum peak height of selected area) and Sv (maximum valley depth of selected area) are of particular interest. A high value Sa in combination with high $\mathrm{Sp}$ and $\mathrm{Sv}$ values indicates a high waviness and thus an inhomogeneous and interrupted paint application. For implants, however, such surfaces are of interest because they grow better into the tissue [18].

Figures 19 and 20 show a two-dimensional view of the surface structure of two different samples with their various respective states. The samples can be separated into a process without control, as shown in Fig. 19 and into a controlled process as shown Fig. 20 regarding the process control of the LMWD-process. Both of them have an nonmachined state and a machined state (turned), whereas the

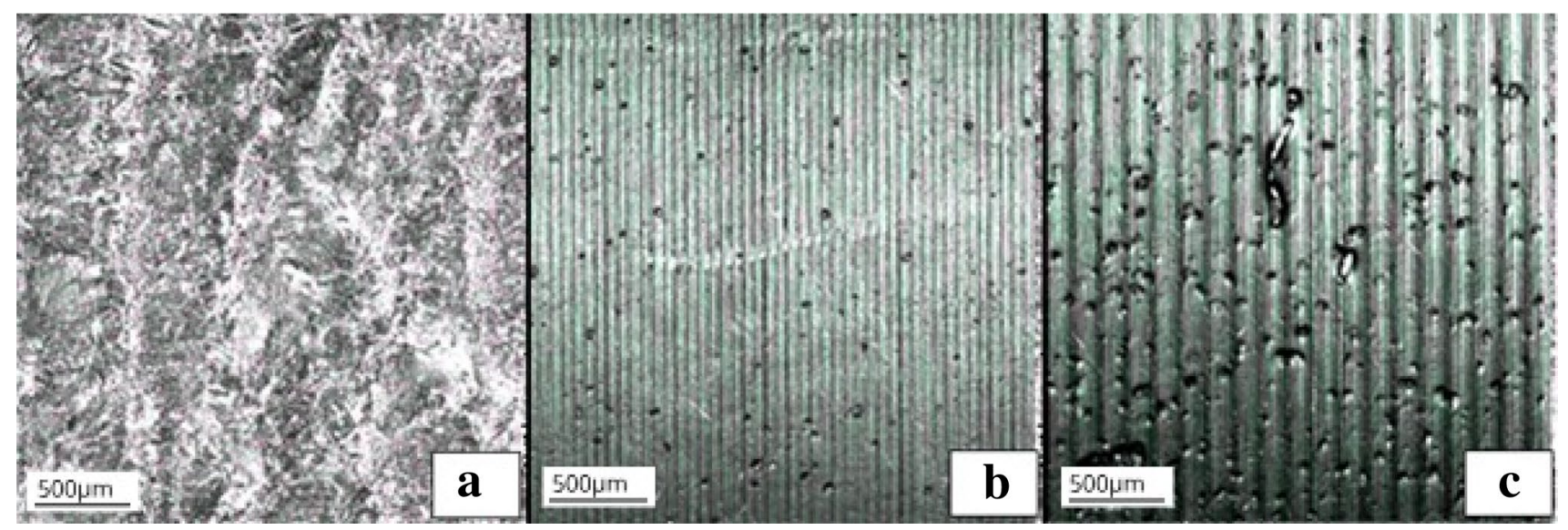

Fig. 19 Surface structure of the samples, 2D-view from an 3D-measurement: a before turning; $\mathbf{b}$ after turning $\left(\mathrm{f}_{1}\right)$; $\mathbf{c}$ after turning $\left(\mathrm{f}_{2}\right)$; process without control 


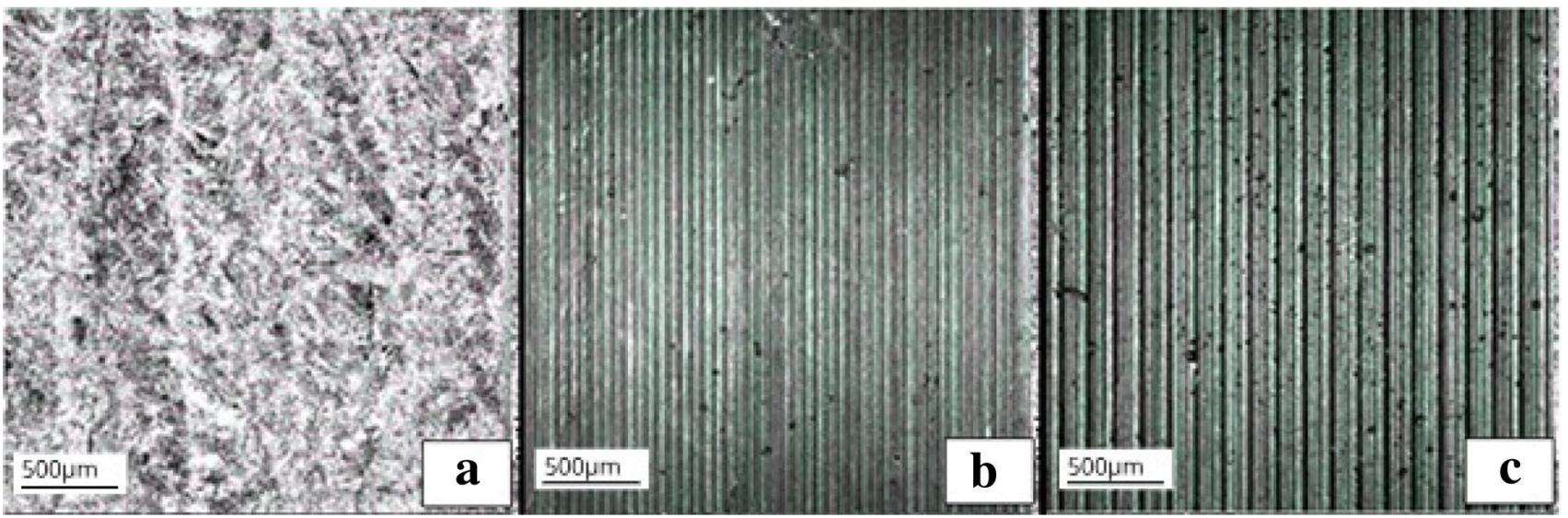

Fig. 20 Surface structure of the samples, 2D-view from an 3D-measurement: a before turning; $\mathbf{b}$ after turning $\left(\mathrm{f}_{1}\right)$; $\mathbf{c}$ after turning $\left(\mathrm{f}_{2}\right)$; process with control B

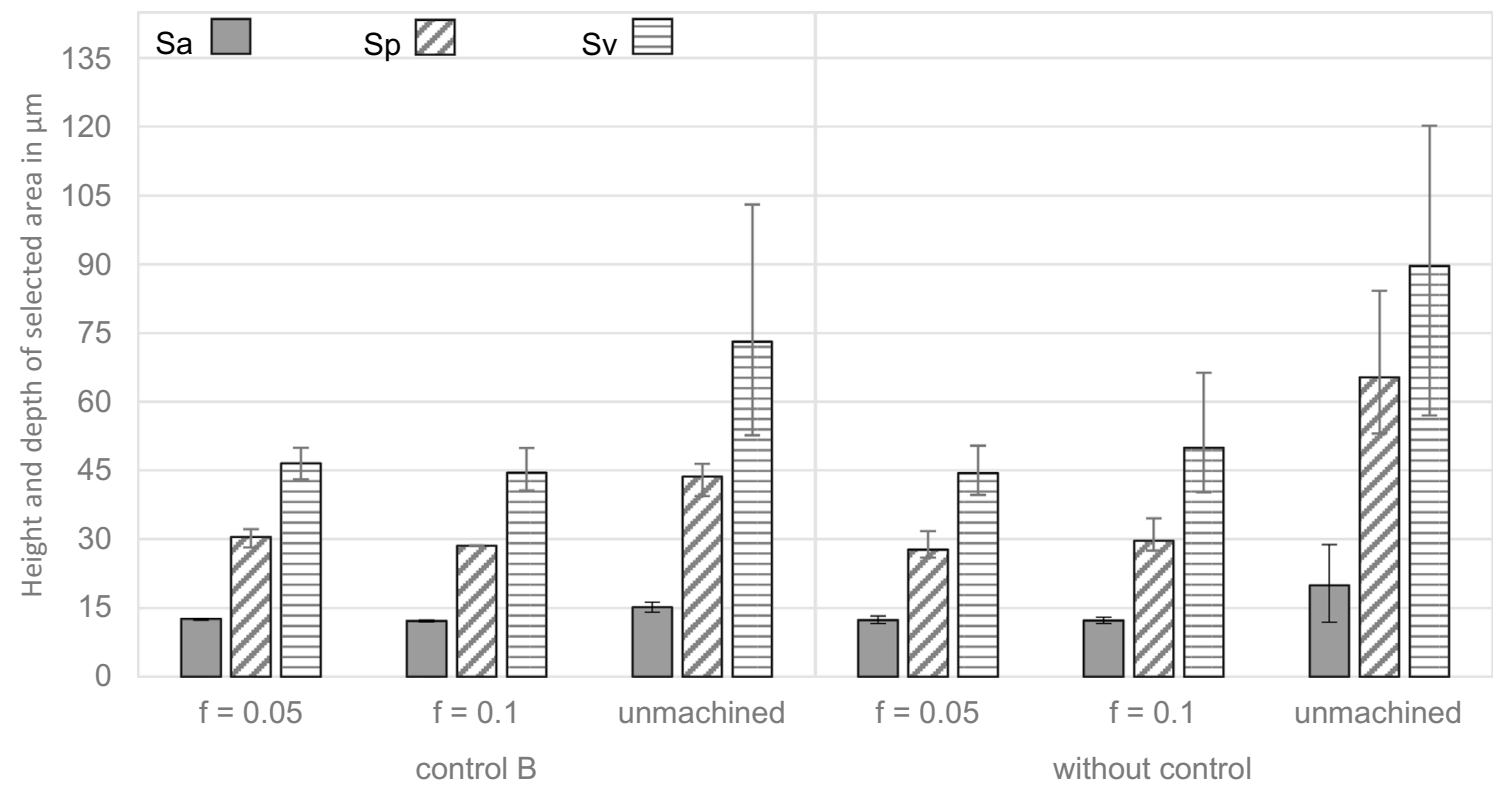

Fig. 21 Height and depth of the selected surface areas before and after machining

machined state separates itself into two different feed rates that were used $(0.05 \mathrm{~mm} / \mathrm{rev}$ and $0.1 \mathrm{~mm} / \mathrm{rev})$ [respective letters (b) and (c)].

Figure 21 illustrates the arithmetic median as well as maxima and minima of the height in the selected measurement areas on the respective sample surface. Figure 21 clearly shows that a controlled process will lead to a more regular and finer surface than an uncontrolled process. The arithmetic median of the height of a controlled process amounts to $\mathrm{Sa}=15.12 \mu \mathrm{m}$ and is comparatively about $24 \%$ lower than an uncontrolled LMWD-process. After subtractive machining operations, the difference between the controlled and uncontrolled process with respect to the Sa-values is levelled out.
Interestingly, the Sa-values of the machined surfaces when compared to one another show only minimal differences, although they have been machined with different feed rates $(\mathrm{f}=0.05 \mathrm{~mm} / \mathrm{rev}$ and $\mathrm{f}=0.1 \mathrm{~mm} / \mathrm{rev}$ ). The arithmetic median of the height of the selected surface amounts to $12-13 \mu \mathrm{m}$ with a maximal height of $\mathrm{Sp}=27-31 \mu \mathrm{m}$. It must be stated that all the examined samples showed high and unstable Sv-values between $120.9-38.7 \mu \mathrm{m}$. Already visually one can identify significant pores that come to existence during the LMWD-process, as shown in Fig. 19 and Fig. 20. After machining operations, these pores drop from $73.04 \mu \mathrm{m}$ to $44.45-46.54 \mu \mathrm{m}$ (controlled process) and from $89.6 \mu \mathrm{m}$ to $44.3-49.9 \mu \mathrm{m}$ (process without control). The surfaces of 
the controlled samples showed little variation with respect to their surface values, which indicates a good repeatability of the whole process (LMWD-process with subsequent machining operations).

It can thus be concluded that these additive-subtractive surfaces with high roughness values can be of interest for e.g. bone implants. This is due to findings by [19] that moderately rough implant surfaces support the differentiation of bone-forming cells in vitro and can achieve rapid and strong bone generation in vivo. Furthermore, the surfaces produced can be considered well suited for soldering processes, provided that certain surface value limits are not exceeded. For applications that require high-quality (smooth) coating surfaces, the surface of the components is rather unsuitable due to the increased $\mathrm{Sv}$ values. However, it cannot be ruled out that satisfactory component surfaces for painting applications can be created through greater material removal in the finishing process.

Figure 22 shows the material volumes and empty volumes of the tested surfaces. These volumes can, for example, characterize the tribological behaviour of pistons in combustion engines. This behaviour is significantly influenced by the real contact surface as well as the contact conditions of the tribological pairing since, within it, the friction and wear mechanisms are primarily at work. For this reason, the values Vmc (material volume of the core area of the surface), Vvc (core void volume) and $\mathrm{Vvv}$ (dale void volume) were examined in detail in the investigations of the surface. The surface of the unmachined process showed comparable material volumes and empty volumes of approx. $18-21 \mathrm{ml} / \mathrm{m}^{2}$ in the core area of the measured surface despite machining. In comparison: For the surface from the unprocessed process the material volumes were $\mathrm{Vmc}=22.56 \mathrm{ml} / \mathrm{m}^{2}$ and the empty volumes $\mathrm{Vvc}=29.26 \mathrm{ml} / \mathrm{m}^{2}$. Overall, this surface showed a strong scattering of the measured volumes in the core region. After machining of components manufactured under controlled conditions, the material volumes are reduced by approx. $8.9 \%(\mathrm{f}=0.05 \mathrm{~mm} / \mathrm{rev})$ and $12.2 \%(\mathrm{f}=0.1 \mathrm{~mm} /$ rev). Correspondingly for the uncontrolled manufactured components, the Vmc value fell by $18.6 \%$ ( $f=0.05 / \mathrm{rev}$ $\mathrm{mm})$ and by $19.8 \%(\mathrm{f}=0.1 \mathrm{~mm} / \mathrm{rev})$ after subtractive machining. The empty volumes of the valleys were at the same level of $\mathrm{Vvv}=2.4-2.9 \mathrm{ml} / \mathrm{m}^{2}$ for the controlled and uncontrolled part surfaces and fell by approx. $30 \%$ (controlled) and $43 \%$ (uncontrolled) after machining.

It can be concluded that the volume parameters of the component surfaces (controlled LMWD process) generally meet the tribological requirements. Due to stable $\mathrm{Vcm}$ values, a homogeneous contact surface can form during tribological contact. The comparable values of $\mathrm{Vvc}$ in the core area can favour the distribution of the lubricant over the nominal contact surface. The $\mathrm{Vvv}$ volumes ensure that the lubricant is retained on the surface. After subtractive machining, all the volumes considered are well preserved.

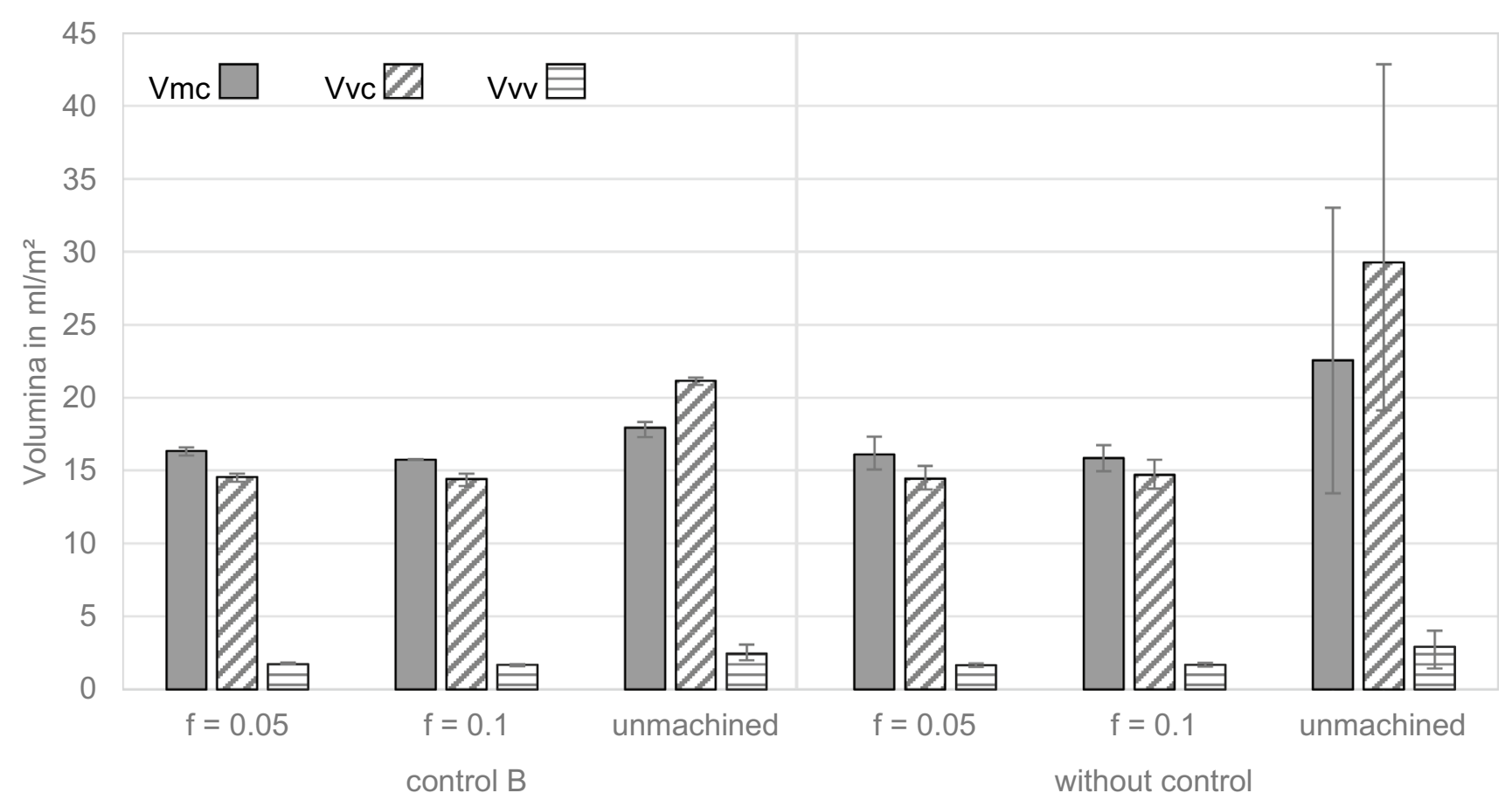

Fig. 22 Material volumes and empty volumes of the selected area before and after machining 
The machined surfaces of the controlled (B) and LMWDprocess without control differ minimally.

\section{Conclusion}

The different influences of laser power on the deposition process were demonstrated. The heating during the building process at constant and reduced power and its effect on the diameter of the cylinder and the height of the individual layers shows the necessity of process control. By means of an OCT based distance measurement a track height control through control of the wire feed rate could be implemented. The track height control leads to a more uniform layer structure of the cylinder and therefore to a smaller deviation from the target geometry. It was shown that with the control in process a minimum wall thickness of the test cylinders of $2.3 \mathrm{~mm}$ can be achieved. For this $9.67 \%$ of the material had to be removed to achieve the final shape of the cylinder (without control 23.07\%).

However, due to the reduced wall thickness and performance of the controlled processes, this was at the expense of the surface roughness of the printed cylinder. Subtractive machining significantly improved the surface roughness of the LMWD-Test samples. The surfaces of the samples produced with a height control showed little variation with respect to their surface values, which indicates a good repeatability of the whole process (LMWD-process with subsequent machining operations).

Acknowledgements The authors would like to thank the Ministry of Science, Research and Arts of the Federal State of Baden-Württemberg for the financial support of the projects within the InnovationsCampus Mobilität der Zukunft. Furthermore, the authors thank Precitec for the loan of the OCT measurement system CHRocodile 2 and the CoaxPrinter.

Funding Open Access funding enabled and organized by Projekt DEAL.

Open Access This article is licensed under a Creative Commons Attribution 4.0 International License, which permits use, sharing, adaptation, distribution and reproduction in any medium or format, as long as you give appropriate credit to the original author(s) and the source, provide a link to the Creative Commons licence, and indicate if changes were made. The images or other third party material in this article are included in the article's Creative Commons licence, unless indicated otherwise in a credit line to the material. If material is not included in the article's Creative Commons licence and your intended use is not permitted by statutory regulation or exceeds the permitted use, you will need to obtain permission directly from the copyright holder. To view a copy of this licence, visit http://creativecommons.org/licenses/by/4.0/.

\section{References}

1. Liu J et al (2018) Current and future trends in topology optimization for additive manufacturing. Struct Multidiscip Optim 57(6):2457-2483. https://doi.org/10.1007/s00158-018-1994-3
2. Ding D, Pan Z, Cuiuri D, Li H (2015) Wire-feed additive manufacturing of metal components: technologies, developments and future interests. Int J AdvManufTechnol 81(1-4):465-481. https:// doi.org/10.1007/s00170-015-7077-3

3. Oyelola $\mathrm{O}$ et al (2020) Machining of directed energy deposited Ti6Al4V using adaptive control. J Manuf Process 54:240-250. https://doi.org/10.1016/j.jmapro.2020.03.004

4. Nowotny S (2009) "Laser-Präzisionsauftragschweißen mit zentrischer Drahtzufuhr: BMBF-Rahmenkonzept "Forschung für die Produktion von morgen"; Ergebnisbericht zum Verbundvorhaben "Flexible 3D-Bearbeitung durch laserbasierte Fügeverfahren mit integrierter Werkstoffzufuhr"; FLEXILAS"

5. Froend M, Riekehr S, Kashaev N, Klusemann B, Enz J (2018) Process development for wire-based laser metal deposition of 5087 aluminium alloy by using fibre laser. J Manuf Process 34:721-732. https://doi.org/10.1016/j.jmapro.2018.06.033

6. Takushima S, Morita D, Shinohara N, Kawano H, Mizutani Y, Takaya Y (2020) Optical in-process height measurement system for process control of laser metal-wire deposition. Precis Eng 62:23-29. https://doi.org/10.1016/j.precisioneng.2019.11.007

7. Garmendia I, Pujana J, Lamikiz A, Flores J, Madarieta M (2019) Development of an intra-layer adaptive toolpath generation control procedure in the laser metal wire deposition process. Materials (Basel, Switz) 12(3):352. https://doi.org/10.3390/ma12030352

8. Kogel-Hollacher M, Strebel M, Staudenmaier C, Schneider H-I, Regulin D (2020) OCT sensor for layer height control in DED using SINUMERIK® controller. In: Laser 3D manufacturing VII: 4-6 February 2020, San Francisco, California, United States, San Francisco, United States, 2020, p 23. [Online]. https://www.spiedigitallibrary.org/conference-proceedings-ofspie/11271/2540167/OCT-sensor-for-layer-height-control-inDED-using-SINUMERIK/https://doi.org/10.1117/12.2540167. full

9. Bär F et al (2019) Laser additive manufacturing of biodegradable magnesium alloy WE43: a detailed microstructure analysis. Acta Biomater 98:36-49. https://doi.org/10.1016/j.actbio.2019.05.056

10. Möhring H-C, Stehle T, Becker D, Eisseler R (2018) Qualität von additiv hergestellten PLA-Bauteilen. wt Werkstattstechnik Online 108(H.6):419-425

11. Möhring H-C, Stehle T, Maucher C, Becker D, Braun S (2019) Predicition of the shape accuracy of parts fabricated by means of FLM process using FEM simulations. J Mach Eng 19(1):114-127. https://doi.org/10.5604/01.3001.0013.0463

12. Williams RJ, Hooper PA, Davies CM (2018) Finite element prediction and validation of residual stress profiles in 316L samples manufactured by laser powder bed fusion. ProcediaStructIntegr 13:1353-1358. https://doi.org/10.1016/j.prostr.2018.12.283

13. Mirkoohi E, Tran H-C, Lo Y-L, Chang Y-C, Lin H-Y, Liang SY (2020) Analytical modeling of residual stress in laser powder bed fusion considering part's boundary condition. Crystals 10(4):337. https://doi.org/10.3390/cryst10040337

14. Lunze J (2020) Regelungstechnik 1: Systemtheoretische grundlagen, analyse und entwurf einschleifiger regelungen, 12th edn. https://doi.org/10.1007/978-3-662-60746-6

15. DIN EN ISO 4287:2010-07 Geometrische Produktspezifikation (GPS)—Oberflächenbeschaffenheit: TastschnittverfahrenBenennungen, Definitionen und Kenngrößen der Oberflächenbeschaffenheit, 4287:2010-07, Deutsches Institut für Normung e.V., Berlin

16. Ingersoll Werkzeuge GmbH (2020) Technisches Handbuch Drehen, Stechen \& Gewindedrehen. [Online]. https://www.ingersollimc.de/fileadmin/user_upload/user_upload/pdfs/Handbuecher/ THB_Drehen_DE.pdf. Accessed 19 Dec 2020

17. Walter AG (2020) Online-Werkzeugkatalog. [Online]. https:// www.walter-tools.com/de-de/search/pages/default.aspx\#/produ ct/DCGT11T304-FN2\%20WNN10. Accessed 9 Nov 2020 
18. Schmid P (2011) Vergleichende Rauigkeitsuntersuchungen von Dentalimplantaten mittels Elektronenmikroskopie und optischer Mikroskopie. Dissertation an der Medizinischen Fakultät der Eberhard Karls Universität Tübingen

19. Piattelli A, Degidi M, Lezzi A (2014) Implantantoberflächen und Fraktale. [Online]. https://www.zmk-aktuell.de/fachgebiete/impla ntologie/story/implantatoberflaechen-und-fraktale__1079.html. Accessed 19 Feb 2021

Publisher's Note Springer Nature remains neutral with regard to jurisdictional claims in published maps and institutional affiliations. 